\title{
(6) OPEN ACCESS \\ Rapid acting fentanyl formulations in breakthrough pain in cancer. Drug selection by means of the System of Objectified Judgement Analysis
}

\author{
Robert Janknegt, ${ }^{1}$ Marieke van den Beuken, ${ }^{2}$ Sjouke Schiere, ${ }^{3}$ Michael Überall, ${ }^{4}$ \\ Roger Knaggs, ${ }^{5,6}$ Jaquie Hanley, ${ }^{7}$ Morten Thronaes ${ }^{8}$
}

For numbered affiliations see end of article.

\section{Correspondence to Dr Robert Janknegt,} Department of Clinica Pharmacy and Toxicology, Zuyderland Medisch Centrum, PO Box 5500, Sittard 6130 $\mathrm{MB}$, The Netherlands; r.janknegt@zuyderland.nl

Received 4 October 2016 Revised 17 November 2016 Accepted 28 November 2016 Published Online First 11 January 2017

EAHP Statement 2: Selection, Procurement and Distribution

\begin{abstract}
Drug selection of rapid acting fentanyl formulations in the treatment of breakthrough pain in patients with cancer is performed by the System of Objectified Judgement Analysis method. All seven available formulations were included in the analysis. The following selection criteria were used: number of available strengths, variability in the rate of absorption, interactions, clinical efficacy, side effects, ease of administration and documentation. No direct doubleblind comparative studies between two or more formulations were identified and the clinical documentation of all formulations is limited. The most distinguishing criterion was ease of use. This led to slightly higher scores for Abstral, Instanyl and PecFent than for the other formulations. The pros and cons of each formulation should be discussed with the patient, and the most suitable formulation selected for each individual patient.
\end{abstract}

\section{INTRODUCTION}

Pain is a common symptom of cancer, ${ }^{1-3}$ which is often feared by patients and healthcare professionals. Strong opioids, such as morphine, oxycodone or fentanyl are the mainstay for the maintenance treatment of severe cancer pain. ${ }^{4}$ They are usually effective in the management of background pain, but breakthrough pain (BTP) may still occur during treatment with slow release opioids.

The term BTP was first described by Portenoy and Hagen in 1989 as "a transitory increase in pain to greater than moderate intensity which occurs on a baseline pain of moderate intensity or less". 5 Thereafter, several definitions have been proposed. ${ }^{6}$ BTP may occur while slow release opioids are being used. ${ }^{7}$ This pain may be caused by actions of the patient such as movement or coughing but may fluctuate for no identifiable reason. BTP should be distinguished from exacerbations of pain that are dose related, such as pain occurring shortly before the next dose of analgesia (end of dose failure). ${ }^{7}$ Treatment of BTP may require rescue doses of strong opioids. ${ }^{8}$

BTP is highly variable, ${ }^{9}$ with a prevalence ranging from $40 \%$ to $80 \%,{ }^{10}$ but prevalence rates of $90 \%$ have been reported ${ }^{11}$ and may result from the disease itself, disability caused by cancer, anticancer treatment or other factors. It usually has a rapid onset - that is, a time to peak severity of 5-30 min, but with a wide range extending to
1 hour (E12). Its duration is often shortlasting and $<60$ min but may last for $>3$ hours. BTP may be nociceptive, neuropathic or a mixture of both. ${ }^{3}$ Cancer BTP is often severe and can greatly interfere with all aspects of daily living. ${ }^{9}{ }^{12}$

Immediate release morphine or oxycodone formulations are extensively used in the treatment of BTP, but their pharmacokinetic characteristics have limitations, with a relatively slow onset of action (up to 1 hour) and duration of action of up to 6 hours. This means that drugs with a quicker onset and shorter duration of action are needed. ${ }^{13}$ Rapid acting, transmucosal, fentanyl formulations have been introduced in the past few years and these are licensed for the treatment of BTP. These formulations are assessed and reviewed in this article.

\section{METHODOLOGY}

The System of Objectified Judgement Analysis (SOJA) method is a model for rational drug selection. ${ }^{14}$ The relevant selection criteria for a group of drugs are defined and judged by a panel of experts. The more important that a selection criterion is considered, the higher the relative weight that is given to that criterion. The ideal properties for each selection criterion are determined and each drug is scored as a percentage of the relative weight for all selection criteria. The criteria, which were used in the present SOJA method for rapid acting fentanyl formulations and the weighting of the authors is presented in table 1 .

A Medline search was performed in September 2013 and repeated in April 2016 and finally 30 September 2016 using search terms 'fentanyl' and 'breakthrough pain' and all relevant articles regarding pharmacokinetics, efficacy (especially randomised controlled studies in BTP in patients with cancer) and safety were included in the manuscript.

The present score is specific for the Netherlands, as the Dutch formulations and approved indications were used for calculation of the score.

The fast acting fentanyl formulations which were available in the Netherlands, Germany and the UK were included in the analysis. These are summarised in table 2 .

The sublingual orally disintegrating tablet (Abstral) should be administered directly under the tongue at the deepest part. The tablet falls apart almost immediately into small particles bound to a mucoadhesive component. After adhesion, this component dissolves resulting in release of fentanyl. The sublingual tablet should not be 
Table 1 Selection criteria and authors' weighting

\begin{tabular}{lr}
\hline Criteria & RWF \\
\hline Number of strengths & 60 \\
Variability in rate of absorption & 50 \\
Interactions & 50 \\
Clinical efficacy & 350 \\
Side effects & 150 \\
Dosage frequency/ease of administration & 140 \\
Documentation & 200 \\
Total weight & 1000 \\
\hline RWF, rating weight factor. &
\end{tabular}

swallowed, but allowed to completely dissolve in the sublingual cavity without chewing or sucking. Patients should be advised not to eat or drink anything until the sublingual tablet is completely dissolved. In patients who have a dry mouth water may be used to moisten the buccal mucosa before taking the sublingual tablet. ${ }^{15}$

The sublingual tablet (Recivit) contains fentanyl in the outer layers of the tablet. Any of the tablet remaining can be swallowed after 30 min. $^{16}$

Oral transmucosal fentanyl citrate (OTFC) is intended for oromucosal administration, and therefore should be placed in the mouth against the cheek and should be moved around the mouth using the citrate-containing sugar matrix on an applicator, with the aim of maximising the amount of mucosal exposure to the product. The OTFC unit should be sucked, not chewed, as absorption of fentanyl via the buccal mucosa is rapid in comparison with systemic absorption via the gastrointestinal tract. Water may be used to moisten the buccal mucosa in patients with a dry mouth. The OTFC unit should be consumed over a 15 min period. If signs of excessive opioid effects appear before the Actiq unit is fully consumed it should be immediately removed, and consideration given to reducing future dosages. ${ }^{17}$

The buccal tablet (Effentora) is an effervescent formulation, using the OraVescent drug delivery technology. The formulation initially lowers local $\mathrm{pH}$, making fentanyl more soluble in saliva. Next carbon dioxide is released, resulting in a higher $\mathrm{pH}$ increasing the proportion of (dissolved) fentanyl that is un-ionised, which allows absorption. Carbon dioxide also increases the permeability of the mucosal tissue. The tablet has to be placed within the buccal cavity above a rear molar between the upper cheek and gum and must be kept in place until it disintegrates (usually 14-25 min). The tablet should not be sucked, chewed or swallowed, as this will result in lower

Table 2 Included fentanyl formulations

\begin{tabular}{|c|c|c|}
\hline Formulation & Trade name & Description \\
\hline Sublingual & Abstral & $\begin{array}{l}\text { Sublingual fentanyl orally disintegrating } \\
\text { tablet }\end{array}$ \\
\hline Sublingual & $\begin{array}{l}\text { Recivit, Ethyfyl, } \\
\text { Dolofent }\end{array}$ & Sublingual fentanyl tablet \\
\hline Oromucosal & Actiq & Oral transmucosal fentanyl citrate \\
\hline Buccal tablet & Effentora & Effervescent formulation \\
\hline $\begin{array}{l}\text { Buccal soluble } \\
\text { film }\end{array}$ & Breakyl & Fentanyl buccal soluble film \\
\hline Nasal spray & Instanyl & Phosphate-buffered solution \\
\hline Nasal spray & PecFent & Fentanyl pectin intranasal spray \\
\hline
\end{tabular}

plasma concentrations than when taken as directed. It may be used sublingually, but clinical studies with this application are lacking. ${ }^{18}$

The fentanyl buccal soluble film (Breakyl) uses the BEMA (BioErodible MucoAdhesive) technology. The BEMA drug delivery technology consists of a small, bioerodible polymer film for application to the mucosal membranes (inner lining of cheek). BEMA films were designed to rapidly deliver a dose of drug across the mucous membranes for time-sensitive conditions or to facilitate administration of drugs with poor oral (pill) absorption. The patient should open the Breakyl sachet immediately before use as indicated by the instructions printed on the sachet and use their tongue to moisten the inside of their cheek or rinse their mouth with water to moisten the area for placement of the buccal film inside the mouth so that the pink side makes smooth contact with the inner lining of the cheek. The patient should press and hold it in place for a minimum of $5 \mathrm{~s}$ until it sticks firmly; then the white side should be visible.

The Breakyl buccal film should stay in place on its own after this period. Liquids may be consumed after $5 \mathrm{~min}$. The Breakyl buccal film will usually dissolve completely within 15-30 min after application. The patient should be instructed to avoid manipulating the buccal film with their tongue or finger(s) and avoid eating food until the buccal film has dissolved. ${ }^{19}$

The intranasal fentanyl spray (Instanyl) contains a phosphatebuffered solution of fentanyl citrate that is administered via a single- or multidose nasal spray device. This drug is rapidly absorbed with an arterial Tmax of $7 \mathrm{~min}$ and an onset time to achieve pain relief (PR) of about 7-10 min (E14). The duration of action is about $60 \mathrm{~min}$ when delivered in single bolus dose. Cleaning of the nasal spray tip is required after each use. ${ }^{20}$

The other nasal spray (PecFent) uses the PecSys drug delivery system (a pectin-based drug delivery system). A low-viscosity aqueous solution contains pectin. Each spray droplet forms a gel after contact with the nasal mucosa.

To administer the nasal spray the nozzle is placed a short distance (about $1 \mathrm{~cm}$ ) into the nostril and pointed slightly towards the bridge of the nose. A spray is then administered by pressing and releasing the finger grips on either side of the nozzle. An audible click will be heard and the number displayed on the counter will advance by one. Patients must be advised that they may not feel the spray being administered, and that they should therefore rely on the audible click and the number on the counter advancing to confirm that a spray has been delivered. Patients should be advised not to blow their nose immediately after administration of the drug. ${ }^{21}$

\section{NUMBER OF AVAILABLE STRENGTHS}

If many different strengths are available, this allows the patient to optimise the effective dosage during the titration period. The available strengths are as follows:

- $\geq 6$ strengths: $100 \%$

- 5 strengths: $90 \%$

- 4 strengths: $80 \%$

- 3 strengths: $70 \%$

- 2 strengths: $60 \%$

- 1 strength: $50 \%$.

Strengths for the different formulations are shown in table 3.

A second dose of Instanyl is allowed after $10 \mathrm{~min}$, which reduces the need for many formulations. PecFent can be given in one or in two nostrils, allowing flexible dosing with only two formulations. On the other hand, this means an extra dose for the patient, which is why we scored this in the present way. 
Table 3 Strengths for the formulations

\begin{tabular}{|c|c|c|c|}
\hline Formulation & Trade name & Strengths $(\mu g)$ & Score $(\%)$ \\
\hline Sublingual & Abstral & $\begin{array}{l}100 \\
200300 \\
400 \\
600 \\
800\end{array}$ & 100 \\
\hline Sublingual & Recivit & $\begin{array}{l}67 \\
133 \\
267 \\
400 \\
533\end{array}$ & 90 \\
\hline Oromucosal OTFC & Actiq & $\begin{array}{l}200 \\
400 \\
600 \\
800\end{array}$ & 80 \\
\hline Buccal tablet & Effentora & $\begin{array}{l}100 \\
200 \\
400 \\
600 \\
800\end{array}$ & 90 \\
\hline Buccal soluble film & Breakyl & $\begin{array}{l}200 \\
400 \\
600 \\
800\end{array}$ & 80 \\
\hline Nasal spray & Instanyl & $\begin{array}{l}50 \\
100 \\
200\end{array}$ & 70 \\
\hline Nasal spray & PecFent & $\begin{array}{l}100 \\
400\end{array}$ & 60 \\
\hline
\end{tabular}

The results reflect the Dutch situation; there may be minor differences in the availability of formulations in other countries.

\section{VARIABILITY OF ABSORPTION}

A wide variety of pharmacokinetic properties may be used to aid selection of fentanyl formulations, but only a few have any clinical relevance. Factors such as protein binding, volume of distribution, route of elimination and lipophilicity have little or no effect on the efficacy and tolerability of fentanyl.

Variability in dose requirements may occur because of differences in drug exposure, and incomplete absorption or a high variability will make dose titration more troublesome.

The variability of the area under the curve (AUC) was used for calculation of the score and was related to the SD of the AUC. Those products with lower SD were awarded a higher score, using the following system:

SD 40\%: score 60\% (100-60\%).

SD 80\%: score 20\% (100-80\%).

\section{Results}

This criterion was given a low relative weight. A high variability in the extent and rate of absorption may certainly contribute to the variability in clinical response, but a very high variability is seen in the clinical response to each individual dosage of every formulation. Thus, the role of pharmacokinetic variability is limited in a comparison of the drugs.

Various studies were not included in the analysis because they used different formulations from those described above.

The absorption of the sublingual formulation (studied for Abstral) may be slower in patients with low salivary flow rates. Moistening of the oral cavity may overcome this. ${ }^{22}$
The presence of mild mucositis had a limited effect on the pharmacokinetics of the buccal tablet, dose $200 \mu \mathrm{g}$. The mean maximum plasma concentration (Cmax) was 1.14 in patients with mucositis and 1.21 in patients without mucositis. ${ }^{23}$

An additional study investigated the intraindividual variability in the AUC and Cmax of the buccal tablet. A low variability was found: the coefficient of variation was $11 \%$ for the Cmax and $7 \%$ for the AUC. ${ }^{24}$ Three pharmacokinetic studies were performed in Japanese volunteers ${ }^{25-27}$ and the AUC and Cmax were consistently higher in Japanese than in Caucasian patients.

The tmax is of course a relevant aspect for the treatment of BTP in cancer. The number of comparative studies is, however, too small to include this as a selection criterion. Two studies compared a buccal tablet and the transmucosal formulation, showing a quicker absorption of the buccal tablet. ${ }^{28} 29$

One pilot study showed a high variability of absorption of Instanyl, probably because of a poor inhalation technique. ${ }^{30}$

Data concerning the variability of the AUC (expressed as the percentage point SD in the tmax) are summarised in table 4 .

No major differences in variability were seen. The variability of the sublingual and nasal formulations was slightly less than that of the other formulations.

\section{DRUG INTERACTIONS}

Drug interactions usually occur in a small minority of patients, but are relevant from a formulary point of view in order to reduce the incidence and severity of these interactions.

This criterion is a standard aspect of the SOJA methodology, but its relevance is low because only fentanyl formulations are included in this analysis and hence this criterion was awarded a score of 50/1000.

If a drug has a high incidence of interactions, this may complicate treatment with this drug. The lower the incidence and

Table 4 Variability of the area under the curve (AUC)*

\begin{tabular}{|c|c|c|c|c|c|}
\hline Formulation & Trade name & Range (\%) & Mean (\%) & Reference & Score $(\%)$ \\
\hline Sublingual & Abstral & $\begin{array}{l}27-35 \\
32\end{array}$ & 32 & $\begin{array}{l}31 \\
32\end{array}$ & 68 \\
\hline Sublingual & Recivit & 34 & 34 & Data on file & 66 \\
\hline Oromucosal & Actiq & $\begin{array}{l}33 \\
56-97 \\
30-62 \\
37\end{array}$ & 48 & $\begin{array}{l}33 \\
34 \\
35 \\
36\end{array}$ & 52 \\
\hline Buccal tablet & Effentora & $\begin{array}{l}40-52 \\
35 \\
52 \\
35 \\
46 \\
47-52 \\
34 \\
47 \\
42 \\
27 \\
27 \\
25\end{array}$ & 40 & $\begin{array}{l}37 \\
38 \\
39 \\
40 \\
18 \\
41 \\
42 \\
43 \\
28 \\
24 \\
25 \\
26\end{array}$ & 60 \\
\hline Buccal tablet & Breakyl & $\begin{array}{l}20-32 \\
33 \\
40\end{array}$ & 33 & $\begin{array}{l}44 \\
36 \\
45\end{array}$ & 67 \\
\hline Nasal spray & Instanyl & $\begin{array}{l}26 \\
40 \\
29-45\end{array}$ & 35 & $\begin{array}{l}46 \\
47 \\
48\end{array}$ & 65 \\
\hline Nasal spray & PecFent & $\begin{array}{l}8-49 \\
58\end{array}$ & 40 & $\begin{array}{l}49 \\
50\end{array}$ & 60 \\
\hline
\end{tabular}

${ }^{*} \mathrm{AUC}$, variability (standardised to $400 \mu \mathrm{g}$ ). 
severity of drug interactions with each individual drug, the higher the score for this criterion.

\section{Results}

The simultaneous use of other central nervous system depressants, including other opioids, sedatives or hypnotic agents, general anaesthetics, phenothiazines, tranquillisers, skeletal muscle relaxants, sedating antihistamines and alcohol may produce additive depressant effects. ${ }^{15-21}$

Fentanyl is metabolised mainly by the cytochrome P450, CYP3A4. Potential interactions may occur when fentanyl is given concurrently with products that affect CYP3A4 activity. Concomitant use with strong CYP3A4 inhibitors may result in increased fentanyl plasma concentrations, with the risk of serious adverse drug reactions, whereas inducers may lower fentanyl concentrations. ${ }^{15-21}$ This is true for all formulations of fentanyl with no clinically relevant differences between them.

Peak fentanyl concentrations and clinical effects were minimally affected by rifampicin or grapefruit juice, but rifampicin reduced the bioavailability of fentanyl by over $60 \%$. No published data are available on the effects of other inducers of CYP3A4 on the pharmacokinetics of transmucosal fentanyl.

The summary of product characteristics of the nasal spray (Instanyl) mentions an interaction with oxymetazoline. The Cmax was reduced by about $50 \%$, whereas the time to reach the peak level was doubled. The combination should be avoided. $^{20}$

All formulations are awarded $80 \%$.

\section{CLINICAL EFFICACY}

Clinical efficacy is by definition a very important selection criterion for each group of drugs. The relative efficacy of the fentanyl formulations was determined using double-blind, randomised comparative studies between these drugs in the first instance.

If these studies were not available, results from randomised placebo-controlled studies or (double-blind or open-label) studies with other rescue opioids were also taken into consideration.

As the last step non-comparative studies were considered. Studies with fewer than 20 patients in each treatment arm $^{51-56}$ were not taken into consideration. Only studies with patients with cancer pain were included in our analysis and those with patients with non-cancer pain or with a mixed population were excluded.

Various endpoints are used to determine clinical efficacy.

- Pain intensity is usually determined on an 11-point scale in which 0 means no pain at all and 10 means pain as bad as one can imagine.

- Pain intensity difference (PID) between placebo and active medication is calculated by subtracting the placebo PI from the PI with the active compound at various time intervals, usually baseline, 15, 30, 45 and $60 \mathrm{~min}$.

- The sum of the PIDs (SPID) may be calculated over time as an alternative endpoint. There is a tendency for greater statistical differences using these outcomes than using the responder rate. ${ }^{57}$

- Another endpoint can be clinically meaningful PI reduction. A PI reduction of $>30 \%$ or $>50 \%$ is the most common endpoint.

- Finally, PR or total PR over time (TOTPAR) are used as endpoints.
We suggest referring to other publications for a more in-depth assessment of the rationale for using each of the endpoints. 5758

\section{Results}

Double-blind randomised comparative studies between two or more fentanyl formulations.

Unfortunately, no studies comparing different rapid action formulations were identified. Such studies are not easy to perform, because cooperation of at least two companies is necessary in order to allow a double-blind, double-dummy (crossover) design. It is therefore unlikely that these studies will be performed in the near future. This makes it complicated to draw conclusions about the relative efficacy (and tolerability) of different fentanyl formulations. In the absence of such studies, authors have tried to compare these drugs indirectly.

Open-label randomised comparative studies between two or more fentanyl formulations.

\section{OTFC versus nasal spray}

One study compared OTFC and the nasal spray in patients with breakthrough cancer pain. ${ }^{59}$ A total of 139 patients were randomised and titrated to an effective dose (at least three of four BTP periods had to be treated effectively) of one of the formulations for six BTP periods, followed by the same procedure for the other formulation. The primary outcome was patientrecorded time to onset of meaningful PR. Secondary outcomes were PID at 10 and $30 \mathrm{~min}$, SPID at 15 and $60 \mathrm{~min}$, ease of administration, treatment preference and relationship between background opioid dose and effective fentanyl dose. The study details are summarised in tables 5-8.

A total of 86 patients completed the study. The endpoint of the study (meaningful PR) was different from the endpoints used in placebo-controlled studies (see below). The median time to onset of meaningful PR was 16 min for OTFC versus $11 \mathrm{~min}$ for the nasal spray. A quicker onset of PR with the nasal spray was found in $66 \%$ of patients $(p<0.001)$. The nasal spray also had significantly $(\mathrm{p}<0.001)$ stronger effects on PIDs at $10(2.27$ vs 1.08 ) and $30 \mathrm{~min}$ (4.15 vs 3.39 ). The PID differences at 5 , 15,20 and $60 \mathrm{~min}$ were also significantly greater for the nasal formulation.

The SPIDs from 0 to 15 (1.66 vs 0.85$)$ and from 0 to $60 \mathrm{~min}$ (3.52 vs 2.83) were greater for the nasal formulation than for the OTFC formulation. ${ }^{59}$ The reasons for withdrawal (adverse events, inadequate analgesia during the titration period, withdrawal of consent) were comparable for both formulations.

It should be considered that (according to the respective summaries of product characteristics) a second dose of the nasal formulation was allowed after $10 \mathrm{~min}$, whereas this was $30 \mathrm{~min}$ for the OTFC formulation. This might have had an effect on the outcomes of the study.

The study was critically discussed in the European Medicines Agency Assessment Report for Instanyl, with a mention of possible misconduct at one of the leading study sites: http:// www.ema.europa.eu/docs/en_GB/document_library/EPAR_Public_assessment_report/human/000959/WC̄ 500033144.pdf $\overline{\text { f }}$ (accessed 18 Sep 2013).

\section{Fentanyl pectin nasal spray versus nasal spray}

One study compared the fentanyl pectin nasal spray (FPNS) and the nasal spray in patients with breakthrough cancer pain in a crossover design in which one to four episodes of BTP were treated. ${ }^{60}$ A total of 97 episodes were treated with the FPNS and 91 with the nasal spray. Contrary to most other 


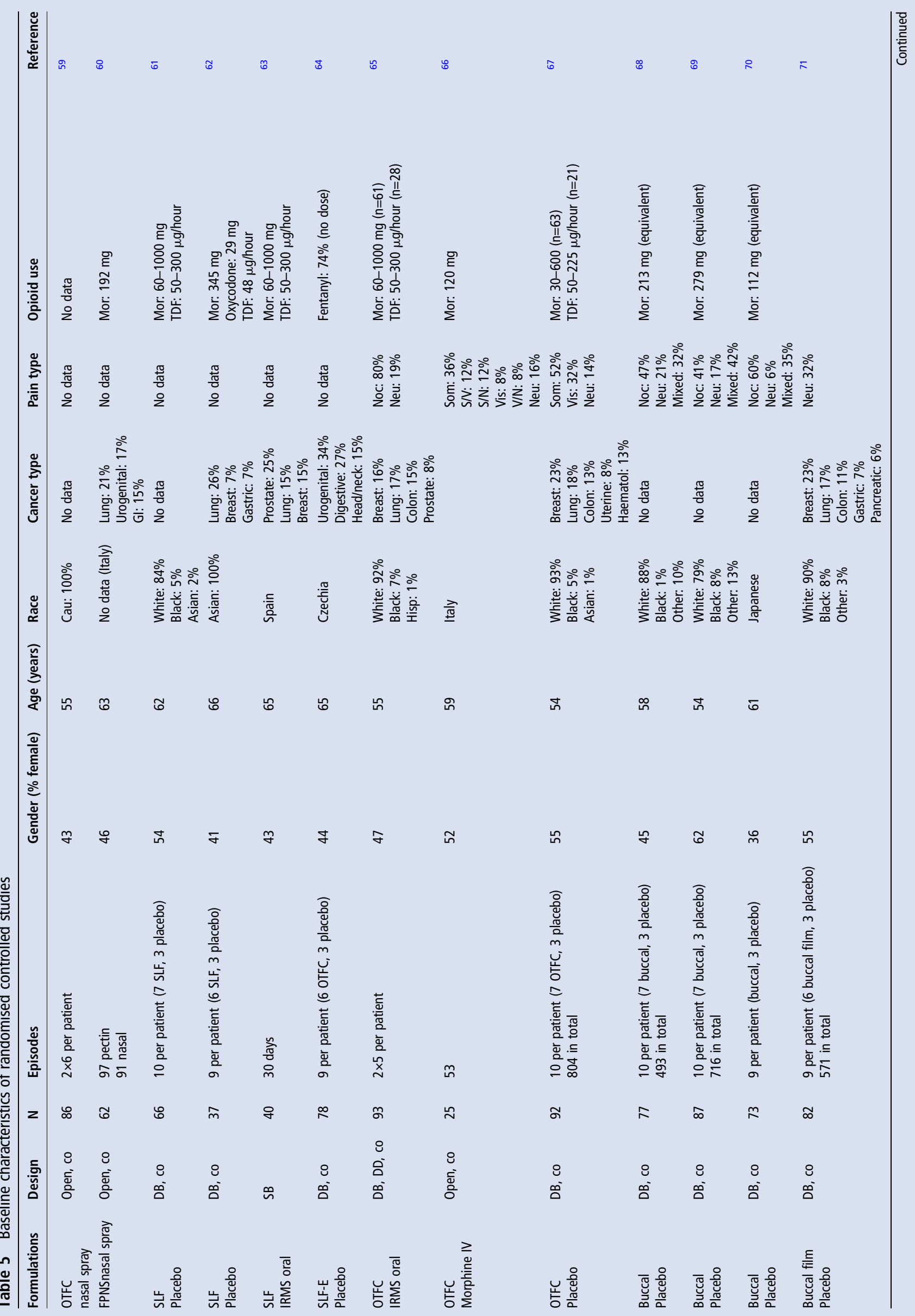




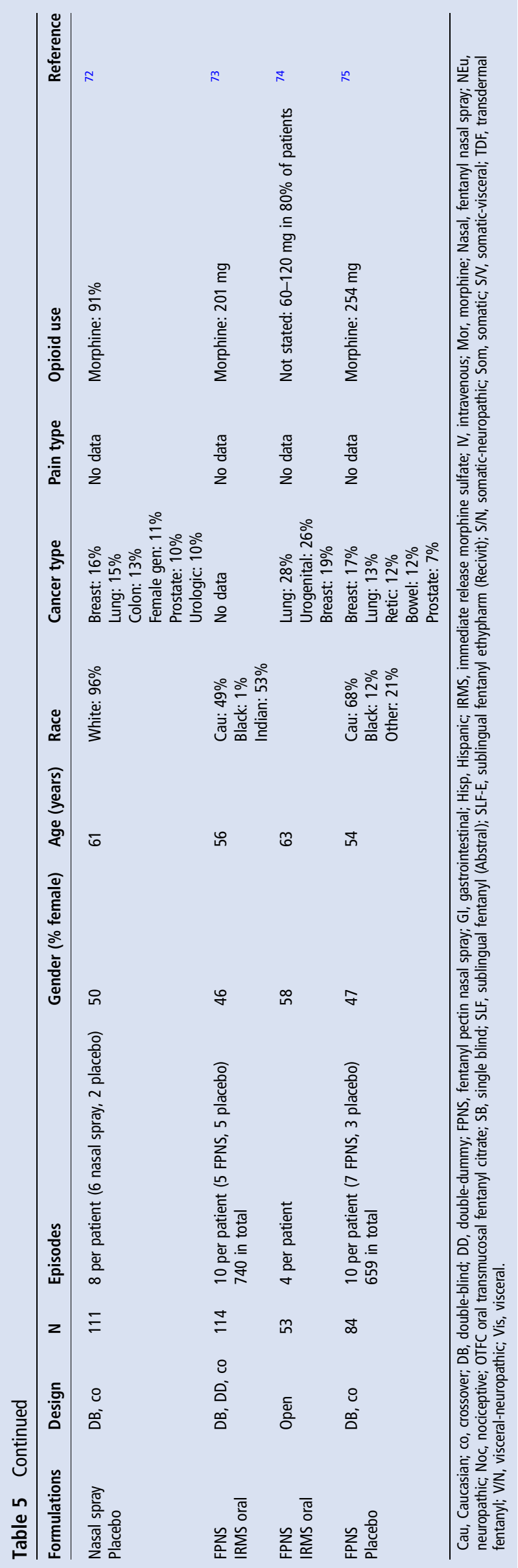

studies no details were presented for the fraction of patients using specific dosages (table 5). The study details are summarised in tables 5-8. PID scores were determined at 5, 10 and $20 \mathrm{~min}$. The PID scores of the FPNS and the nasal spray, respectively, were 1.2 and 1.0 at $5 \mathrm{~min}, 2.4$ and 2.2 at $10 \mathrm{~min}$ and 3.8 and 3.4 at $20 \mathrm{~min}$, compared with baseline. The scores at 5 and $20 \mathrm{~min}$ were significantly better for the FPNS. The SPID scores at $20 \mathrm{~min}$ (7.5 and 6.7) were not significantly different. The FPNS also performed better than the nasal spray at some time points with respect to the proportion of patients showing $>33 \%$ reduction in pain intensity (at $5 \mathrm{~min}$ only) and $>50 \%$ reduction (at 20 min only). ${ }^{60}$

\section{Comparative studies with other active medicines Orally disintegrating sublingual tablet}

One prospective, longitudinal study compared the orally disintegrating sublingual tablet with oral immediate release morphine. ${ }^{63}$ Details of the study are presented in tables 5-8. Patients with breakthrough cancer pain were randomised to start with either the sublingual tablet or with morphine for 30 days and were then titrated to an effective dose of both drugs. The primary endpoints were the pain intensity, frequency of BTP requests and time to onset of relief. Primary endpoints were assessed at days 3 (during titration), 7, 15 and 30. It was not stated when pain intensity was determined related to the dosage of the medicines. The sublingual tablet was better $(p<0.001)$ than oral morphine at all endpoints. At days 7, 15 and 30 statistical significance was reached as early as $5 \mathrm{~min}$ and showed significantly faster time to onset of relief for the sublingual tablet over the oral morphine at all stages $(p<0.001) .{ }^{63}$

\section{OTFC formulation}

One double-blind, double dummy, crossover study compared OTFC with morphine sulfate immediate release oral formulations. ${ }^{64}$ Details of the study are presented in tables 5-8. Patients with BTP were titrated to an effective dose of both drugs and were then randomised to start with either OTFC or with morphine for five doses each. The primary endpoint was the PID score at $15 \mathrm{~min}$. There was no relationship between the OTFC and morphine doses after the titration phase. There were also no relationships between the breakthrough dosages of rescue medication and the dosages of background analgesia.

At 15 min OTFC produced a $>33 \%$ change in PID score for $42 \%$ of treated episodes, compared with $32 \%$ of treated episodes with oral morphine $(\mathrm{p}<0.001)$. OTFC performed better than morphine in its effect on PID $(p<0.008)$, PI $(p \leq 0.033)$ and PR scores $(p \leq 0.009)$ at all time intervals. The percentage of BTP episodes for which patients needed additional medication was similar for both formulations $(2 \%$ and $1 \%$ for OTFC and morphine, respectively). ${ }^{64}$

Another, small-scale study compared OTFC with intravenous morphine. Details of the study are presented in tables 5-8. PID at 15 and $30 \mathrm{~min}$ decreased more than $50 \%$ in $38 \%$ and $75 \%$, respectively, of patients treated with OTFC and in 55\% and $75 \%$ with morphine IV. This difference was significant at $15 \mathrm{~min}$ $(p=0.013)$. No significant difference was seen at $30 \mathrm{~min}$. The effect on PID was also significantly better at $15 \mathrm{~min}$ for morphine. ${ }^{66}$

\section{FPNS}

One double-blind, double dummy, crossover study compared FPNS with immediate release morphine sulfate (IRMS). ${ }^{73}$ The study details are summarised in tables 5-8. The PI scores at baseline were significantly higher for FPNS (7.76) than for 
Table 6 Dose fentanyl formulations in randomised controlled studies

\begin{tabular}{|c|c|c|c|c|c|c|c|c|c|c|}
\hline Formulations & $\begin{array}{l}\text { Dose } \\
\text { fentanyl }\end{array}$ & & & & & & & & Comparator dose & Reference \\
\hline & 50 & 100 & 200 & 400 & 600 & 800 & 1200 & 1600 & & \\
\hline OTFC & - & - & 34 & 30 & 11 & 5 & 5 & 5 & NA & 59 \\
\hline Nasal spray & 23 & 32 & 40 & - & - & - & - & - & & \\
\hline FPNSNasal spray & & & & & & & & & $\begin{array}{l}\text { Pectin: } 328 \mu \mathrm{g} \\
\text { Nasal: } 165 \mu \mathrm{g}\end{array}$ & 60 \\
\hline $\begin{array}{l}\text { SLF } \\
\text { Placebo }\end{array}$ & & 4 & 6 & $\begin{array}{l}7 \\
16(300 \mu g)\end{array}$ & 8 & 21 & & & & 61 \\
\hline $\begin{array}{l}\text { SLF } \\
\text { Placebo }\end{array}$ & & $26 \%$ & $21 \%$ & $\begin{array}{l}10 \% \\
26 \% \\
(300 \mathrm{mg})\end{array}$ & $5 \%$ & $2 \%$ & & & & 62 \\
\hline $\begin{array}{l}\text { SLF } \\
\text { IRMS oral }\end{array}$ & & & $\begin{array}{l}\text { Mean dose } \\
235 \mu \mathrm{g}\end{array}$ & & & & & & Mor: 38 mg & 63 \\
\hline $\begin{array}{l}\text { SLF-E } \\
\text { Placebo }\end{array}$ & & $\begin{array}{l}36 \% \\
(133 \mu g))\end{array}$ & $31 \%(267 \mu \mathrm{g})$ & $14 \%$ & $\begin{array}{l}13 \% \\
(567 \mu g)\end{array}$ & $6 \%$ & & & & 64 \\
\hline $\begin{array}{l}\text { OTFC } \\
\text { IRMS oral }\end{array}$ & & & $10 \%$ & $19 \%$ & $25 \%$ & $15 \%$ & $17 \%$ & $15 \%$ & $\begin{array}{l}15 \mathrm{mg}: 27 \% \\
30 \mathrm{mg}: 46 \% \\
45 \mathrm{mg}: 17 \% \\
60 \mathrm{mg}: 10 \%\end{array}$ & 65 \\
\hline $\begin{array}{l}\text { OTFC } \\
\text { Mor IV }\end{array}$ & & & $24 \%$ & $12 \%$ & $20 \%$ & $4 \%$ & $32 \%$ & $8 \%$ & $\begin{array}{l}\text { Fixed ratio: } 200 / 4 \text {, } \\
\text { etc }\end{array}$ & 66 \\
\hline $\begin{array}{l}\text { OTFC } \\
\text { Placebo }\end{array}$ & No data & No data & No data & No data & No data & $\begin{array}{l}\text { No } \\
\text { data }\end{array}$ & No data & $\begin{array}{l}\text { No } \\
\text { data }\end{array}$ & NA & 67 \\
\hline $\begin{array}{l}\text { Buccal } \\
\text { Placebo }\end{array}$ & & 12 & 11 & 20 & 10 & 24 & & & NA & 68 \\
\hline $\begin{array}{l}\text { Buccal } \\
\text { Placebo }\end{array}$ & & $8 \%$ & $12 \%$ & $18 \%$ & $28 \%$ & $34 \%$ & & & NA & 69 \\
\hline $\begin{array}{l}\text { Buccal } \\
\text { Placebo }\end{array}$ & $7 \%$ & $14 \%$ & $19 \%$ & $17 \%$ & $11 \%$ & $6 \%$ & $\begin{array}{l}27 \% \text { dose not } \\
\text { known }\end{array}$ & & NA & 70 \\
\hline $\begin{array}{l}\text { Buccal film } \\
\text { Placebo }\end{array}$ & & & $5 \%$ & $19 \%$ & $28 \%$ & $24 \%$ & $25 \%$ & & NA & 71 \\
\hline $\begin{array}{l}\text { Nasal spray } \\
\text { Placebo }\end{array}$ & 18 & 48 & 45 & & & & & & NA & 72 \\
\hline $\begin{array}{l}\text { FPNS } \\
\text { IRMS oral }\end{array}$ & & 16 & 18 & 30 & & 15 & & & Mor: 29 mg & 73 \\
\hline $\begin{array}{l}\text { FPNS } \\
\text { IRMS oral }\end{array}$ & & & & & & & & & $\begin{array}{l}\text { Pectin: } 182 \mu \mathrm{g} \\
\text { Mor: } 17 \mathrm{mg}\end{array}$ & 74 \\
\hline $\begin{array}{l}\text { FPNS } \\
\text { Placebo }\end{array}$ & & $11 \%$ & $10 \%$ & $33 \%$ & $47 \%$ & & & & & 75 \\
\hline
\end{tabular}

IRMS (7.65), $\mathrm{p}<0.05$. The primary endpoint was PID at 15 min: 3.0 versus 2.7 , respectively, $p<0.05)$. The PID remained statistically significant at all later time points. No significant difference in the effect on PID was seen after 5 and $10 \mathrm{~min}$. The mean differences in TOTPAR were significantly more favourable for the FPNS from 15 min onwards. More patients achieved a PR score of 4 with FPNS (18\%) than with IRMS at 45 and $60 \mathrm{~min}$, but the difference at $30 \mathrm{~min}$ was not statistically significant. $^{73}$

An analysis of the above study demonstrated TOTPAR $>33 \%$ was statistically significant better for FPNS than IRMS $(p \leq 0.01)$. It also showed statistical significant differences in the percentage of episodes showing clinically meaningful PR (PID scores at 10 min $\mathrm{p}<0.05$ ) in favour of FPNS versus IRMS. The difference between the two products in efficacy outcome measures narrows after $30 \mathrm{~min}$, suggesting that the effect of IRMS and FPNS are similar after this time. Patient acceptability scores were significantly better for FPNS than for IRMS at 30 and 60 min. $^{76}$

An open-label comparative study also showed better efficacy of FPNS than immediate release oral morphine. ${ }^{74}$
No comparative studies with other active medicines are available for sublingual tablet, buccal soluble film, buccal tablet and nasal spray.

\section{Double-blind, placebo-controlled studies \\ Orally disintegrating sublingual tablet}

Two studies have been performed with the sublingual formulation-one a phase II study and one a phase III study. The study details are summarised in tables 5-8. Unfortunately, not all studies provided information about the proportion of patients requiring rescue medication.

One phase II study compared a single dose of 100, 200 and $400 \mu \mathrm{g}$ sublingual fentanyl with placebo in a randomised, crossover fashion in opioid-tolerant patients with cancer. The primary endpoint was PID from baseline, using a $100 \mathrm{~mm}$ Visual Analogue Scale. Pain intensity was recorded at baseline, 5, 10, 15, 20 and $30 \mathrm{~min}$. Secondary endpoints were global assessment of treatment and the need for rescue medication. A total of 38 patients were randomised. Of these, 27 received the study medication and 23 completed the study. There was a significant overall improvement in the PID over the whole period 
Table 7 Patients in randomised controlled studies

\begin{tabular}{|c|c|c|c|c|c|c|c|c|}
\hline Formulations & $\begin{array}{l}\text { Titration } \\
\text { duration } \\
\text { (median) }\end{array}$ & $\begin{array}{l}\mathrm{N} \\
\text { Initial }\end{array}$ & $\begin{array}{l}\text { Withdrawal } \\
\text { titration } \\
\text { phase }\end{array}$ & Randomised & $\begin{array}{l}\text { Withdrawal } \\
\text { study } \\
\text { phase }\end{array}$ & $\begin{array}{l}\text { Evaluable } \\
\text { efficacy }\end{array}$ & Mean dose & Reference \\
\hline $\begin{array}{l}\text { OTFC } \\
\text { Nasal spray }\end{array}$ & $\begin{array}{l}-8 \text { weeks } \\
-5 \text { weeks }\end{array}$ & 196 & 57 & 139 & 53 & 86 & No data & 59 \\
\hline $\begin{array}{l}\text { FPNS } \\
\text { Nasal spray }\end{array}$ & $\begin{array}{l}-8 \text { weeks } \\
-5 \text { weeks }\end{array}$ & 62 & & 62 & 12 & 50 & $\begin{array}{l}\text { Pectin: } \\
328 \mu \mathrm{g} \\
\text { Nasal: } \\
165 \mu \mathrm{g}\end{array}$ & 60 \\
\hline $\begin{array}{l}\text { SLF } \\
\text { Placebo }\end{array}$ & 2 weeks & 131 & 53 & 66 & 6 & 60 & $600 \mu \mathrm{g}$ & 61 \\
\hline $\begin{array}{l}\text { SLF } \\
\text { Placebo }\end{array}$ & 3 weeks & 42 & 5 & 37 & 5 & 32 & No data & 62 \\
\hline $\begin{array}{l}\text { SLF } \\
\text { IRMS oral }\end{array}$ & 7 days & 40 & 0 & 40 & 0 & 40 & $235 \mu \mathrm{g}$ & 63 \\
\hline $\begin{array}{l}\text { SLF-E } \\
\text { Placebo }\end{array}$ & 2 weeks & 91 & 13 & 78 & 5 & 73 & & 64 \\
\hline $\begin{array}{l}\text { OTFC } \\
\text { IRMS oral }\end{array}$ & 5 days & 134 & 41 & 93 & 9 & 75 & $\begin{array}{l}811 \mu \mathrm{g} \\
31 \mathrm{mg}\end{array}$ & 65 \\
\hline $\begin{array}{l}\text { OTFC } \\
\text { Mor IV }\end{array}$ & None & 40 & NA & 40 & 15 & 25 & No data & 66 \\
\hline $\begin{array}{l}\text { OTFC } \\
\text { Placebo }\end{array}$ & 2 weeks & 130 & 37 & 92 & 20 & 72 & No data & 67 \\
\hline $\begin{array}{l}\text { Buccal } \\
\text { Placebo }\end{array}$ & No data & 123 & 46 & 77 & 9 & 77 & No data & 68 \\
\hline $\begin{array}{l}\text { Buccal } \\
\text { Placebo }\end{array}$ & 7 days & 125 & 38 & 87 & 12 & 75 & & 69 \\
\hline $\begin{array}{l}\text { Buccal } \\
\text { Placebo }\end{array}$ & 21 days & 103 & 26 & 73 & 2 & 73 & & 70 \\
\hline $\begin{array}{l}\text { Buccal film } \\
\text { Placebo }\end{array}$ & 7 days & 151 & 69 & 82 & 2 & 80 & & 71 \\
\hline $\begin{array}{l}\text { Nasal spray } \\
\text { Placebo }\end{array}$ & No data & 120 & 7 & 113 & 3 & 110 & & 72 \\
\hline $\begin{array}{l}\text { FPNS } \\
\text { IRMS oral }\end{array}$ & 14 days & 110 & 26 & 84 & 5 & 79 & & 73 \\
\hline $\begin{array}{l}\text { FPNS } \\
\text { IRMS oral }\end{array}$ & No data & 53 & & 53 & 8 & 45 & $\begin{array}{l}\text { Pectin: } \\
182 \mu \mathrm{g} \\
\text { Mor: } 17 \mathrm{mg}\end{array}$ & 74 \\
\hline $\begin{array}{l}\text { FPNS } \\
\text { Placebo }\end{array}$ & & 114 & 31 & 83 & 7 & 73 & & 75 \\
\hline
\end{tabular}

FPNS, fentanyl pectin nasal spray; IRMS, immediate release morphine sulfate; iv, intravenous; Mor, morphine; NA, not applicable; Nasal, fentanyl nasal spray; OTFC oral transmucosal fentanyl citrate; SLF, sublingual fentanyl (Abstral); SLF-E, sublingual fentanyl ethypharm (Recivit).

compared with placebo $(8.6 \mathrm{~mm}, \mathrm{p}<0.0001)$. A significant difference was seen after $15 \mathrm{~min}$. No significant difference was observed between the 100 and $200 \mu \mathrm{g}$ doses compared with placebo. The global assessment of treatment was rated as excellent in nine patients using the $400 \mu \mathrm{g}$ dose versus 3 with placebo $(p=0.0146)$ and fewer patients needed rescue medication: 5 versus $15, \mathrm{p}=0.001$. $^{77}$

A phase III study involving 136 patients compared the sublingual formulation to placebo. Patients were titrated in an openlabel setting, followed by a double-blind, efficacy phase, lasting 2 weeks, in which the titrated dose (seven episodes) was compared with placebo (three episodes). Sublingual fentanyl was associated with a significantly stronger effect on SPID 0-30: 49.5 vs $36.6, p=0.0004$ ) compared with placebo. This was also the case for SPID 0-60: 143 vs $105, \mathrm{p}=0.0002$ ). PID was significantly lowered at all time points from 10 to $60 \mathrm{~min}$, $p=0.0055$, in the sublingual fentanyl group. A greater reduction of PR was seen from 10 to $60 \mathrm{~min},(p=0.049)$ with fentanyl than with placebo. Rescue medication was needed in $11 \%$ of fentanyl users, compared with $27 \%$ with placebo (no statistics were provided), and global evaluation scores were better for fentanyl: 3.1 versus $3.6, \mathrm{p}=0.0006 .^{61}$
One Japanese small-scale study also compared the sublingual formulation with placebo. Patients were titrated during 3 weeks in an open-label setting, followed by a double-blind, efficacy phase, lasting up to 3 weeks, in which the titrated dose (six episodes) was compared with placebo (three episodes). This study used a Visual Analogue Scale of $100 \mathrm{~mm}$ for estimation of PID. Sublingual fentanyl was associated with a statistically significant effect on PID at 30 and $60 \mathrm{~min}$, whereas no significant effect was observed at $15 \mathrm{~min}$. Global assessment of PR was scored on a scale ranging from 4 (no relief at all) to 0 (complete relief). $\mathrm{PR}$ at 30 and $60 \mathrm{~min}$ was significantly better for the sublingual formulation $(\mathrm{p}<0.001)$ than with placebo $(30 \mathrm{~min}: 2.0$ vs 1.5 , and $60 \mathrm{~min}: 1.4$ vs 0.9$).^{62}$

\section{Sublingual tablet (Recivit)}

One phase III study compared the sublingual formulation with placebo. ${ }^{64}$ Patients were titrated in an open-label setting, followed by a double-blind, crossover efficacy phase, in which the titrated dose (six episodes) was compared with placebo (three episodes). Sublingual fentanyl was associated with a statistically significant beneficial effect on SPID at $30 \mathrm{~min}$ compared with placebo (75 vs 53, p<0.0001). This was also the case for SPID, 


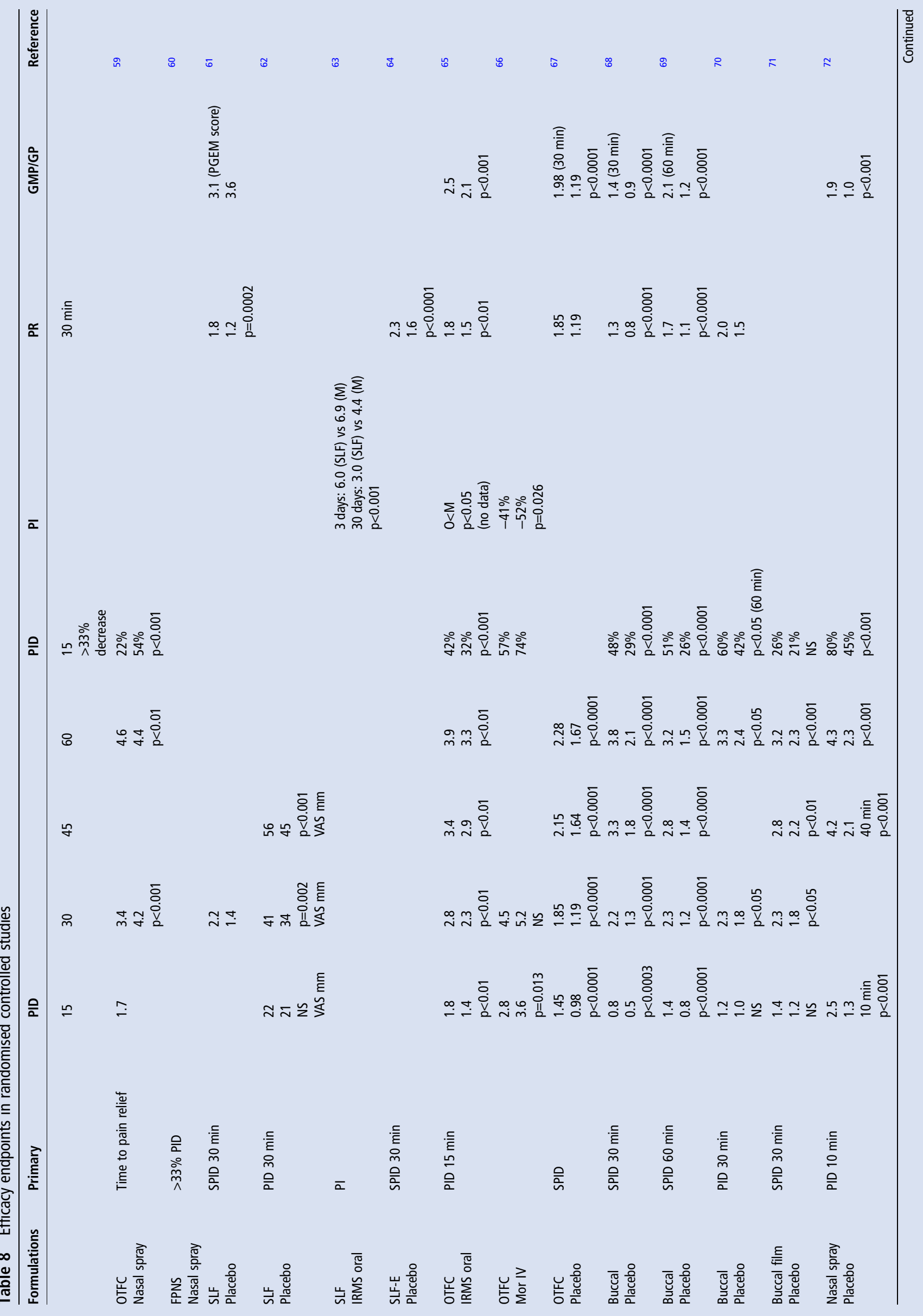




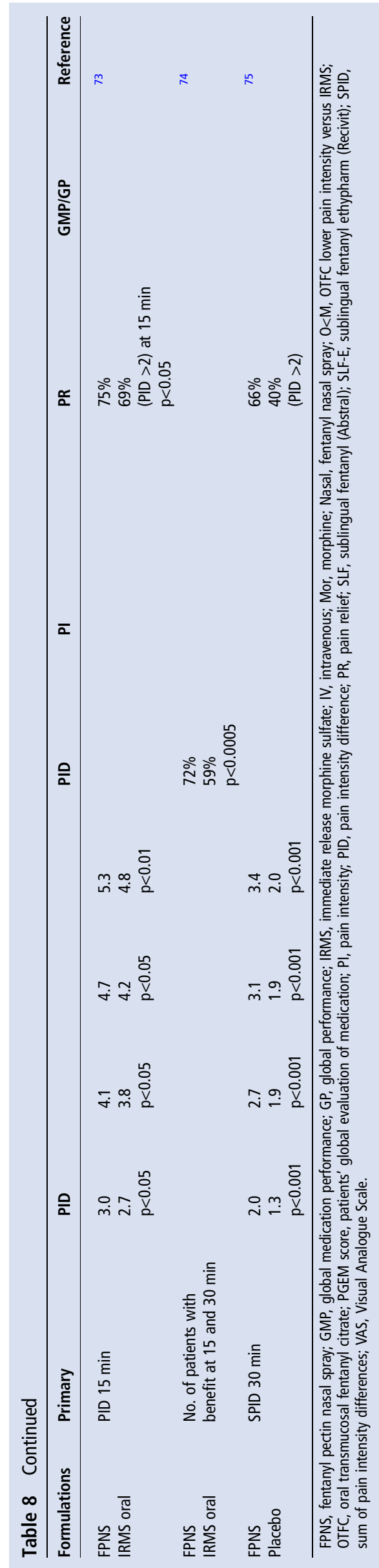

PID, PI and PR scores from 6 to $60 \mathrm{~min}$. At $15 \mathrm{~min}, 58 \%$ of sublingual fentanyl episodes had a pain score reduction of at least $33 \%$, compared with $38 \%$ in the placebo group. At $30 \mathrm{~min}$ these values were $72 \%$ and $51 \%$, respectively, $\mathrm{p}<0.0001)$. Pain reduction of at least $50 \%$ was observed with sublingual fentanyl in $27 \%$ at $15 \mathrm{~min}$ and $53 \%$ at $30 \mathrm{~min}$, and $19 \%$ and $36 \%$ for placebo, respectively ( $\mathrm{p}$ values 0.02 and 0.0004 ). Additional rescue medication for BTP was needed in $18 \%$ of episodes treated with sublingual fentanyl compared with $38 \%$ of episodes treated with placebo $(\mathrm{p}<0.0001) .{ }^{64}$

\section{OTFC formulation}

One study compared OTFC with placebo. ${ }^{67}$ The study details are summarised in tables 5-8. Intention-to-treat analysis showed that OTFC had significantly better effects on pain intensity and PR than placebo at all time intervals assessed $(15,30,45$ and $60 \mathrm{~min}$ ). The need for additional rescue medication was significantly lower in the OTFC group; $15 \%$ vs $34 \%, \mathrm{p}<0.0001$. The majority of patients $(80 \%)$ preferred OTFC rather than placebo. $^{67}$

\section{Buccal tablet}

Three studies compared the buccal tablet with placebo. ${ }^{68-70}$ The study details are summarised in tables 5-8.

One study showed significantly better effects of the buccal tablet than placebo on SPID and TOTPAR scores at 15, 30, 45 and $60 \mathrm{~min}$ ( $\mathrm{p}<0.0001$ for almost all time points). The SPID at 30 min (the primary endpoint) was 3.0 for the buccal tablet versus 1.8 for placebo $(\mathrm{p}<0.0001)$. A $50 \%$ reduction in pain score was seen in $24 \%$ of episodes with the buccal tablet and in $16 \%$ with placebo $(\mathrm{p}=0.0023)$. Supplemental medication was needed in $23 \%$ with the buccal tablet versus $50 \%$ with placebo. This study showed no correlation between an effective dose of fentanyl and background opioid analgesic dose. ${ }^{68}$

The second study provided information on the effects of the buccal tablet on pain of different origins. No clear differences were seen between the SPID for patients with pain of nociceptive, neuropathic or mixed origin. TOTPAR was significantly better in the episodes treated with active medication. At $30 \mathrm{~min}$, a pain intensity reduction of at least $50 \%$ was obtained in $38 \%$ for the buccal tablet versus $15 \%$ in the placebo episodes. ${ }^{69}$

The third study was performed in Japanese subjects. PID was significantly better for the buccal fentanyl product than for placebo from 30 min onwards, but no significant difference was noted at earlier assessments at $15 \mathrm{~min}^{70}$

\section{Buccal film}

One study compared buccal film with placebo. ${ }^{71}$ The study details are summarised in tables 5-8. The primary endpoint was SPID at $30 \mathrm{~min}$. The buccal film scored significantly better than placebo for the primary end point $(p<0.004)$. Statistical significance was seen with the SPID for the buccal film rather than the placebo at 15,45 and $60 \mathrm{~min}$ also ( $\mathrm{p}$ values range $<0.001-$ $<0.05)$. The PID values for buccal film were greater than for placebo with statistical significance seen from 30 min onwards ( $p<0.05$ at $30 \mathrm{~min}, \mathrm{p}<0.01$ at $45 \mathrm{~min}$ and $\mathrm{p}<0.001$ at $60 \mathrm{~min}$ ). The percentage of patients with $>50 \%$ decrease in PI was significantly lower at 30, 45 and $60 \mathrm{~min}$, but not at $15 \mathrm{~min}$. No information was provided about the use of rescue medication, although overall satisfaction scores showed significant preference for the buccal film than for placebo. ${ }^{71}$ 


\section{Nasal spray}

One study compared the nasal spray with placebo. ${ }^{72}$ The study details are summarised in tables 5-8. The primary endpoint was PID at $10 \mathrm{~min}$. A lower PID at $10 \mathrm{~min}$ was found for the $50 \mu \mathrm{g}$ dose (PID 2.0) than for the $100 \mu \mathrm{g}$ (PID 2.7) and $200 \mu \mathrm{g}$ (PID 2.6) doses. By comparison, placebo resulted in a PID of 1.3 at $10 \mathrm{~min}(\mathrm{p}<0.001)$. The difference between the $50 \mu \mathrm{g}$ and the higher dosages was maintained at $60 \mathrm{~min}$. The same effect was seen for the SPID from 0 to $60 \mathrm{~min}$. A PI reduction of $>33 \%$ at $10 \mathrm{~min}$ was observed in $58 \%$ of those treated with the nasal spray compared with $28 \%$ treated with the placebo. Rescue medication was used in $14 \%$ of episodes treated with the nasal spray versus $45 \%$ for placebo. ${ }^{72}$ A further study identified was excluded because fewer than 20 patients were included in each treatment arm. ${ }^{78}$

\section{FPNS}

One study compared fentanyl FPNS with placebo. ${ }^{75}$ The study details are summarised in tables 5-8. The primary endpoint was SPID at $30 \mathrm{~min}$, which was significantly in favour of the FPNS (SPID scores at $30 \mathrm{~min}$ were 6.6 for FPNS and 4.5 for placebo, respectively, $\mathrm{p}<0.0001)$. At 10 and $15 \mathrm{~min}$, a significantly greater proportion of patients had shown a reduction in PI scores of at least one point with the FPNS versus the placebo $(\mathrm{p}<0.01)$. A greater number of placebo-treated episodes needed additional rescue medication compared with FPNS treated episodes. $^{75}$ Patient acceptability was also better for the nasal spray. $^{79}$

\section{Non-comparative studies}

Non-comparative studies or studies comparing different dosage regimens of the same formulation are not included in this analysis, but were taken into consideration for the judgement of safety, when applicable. ${ }^{80-92}$

The number of comparative studies is disappointingly small, which makes it difficult to judge the relative efficacy of different fentanyl formulations. Only one open-label randomised study has been performed: between OTFC and the nasal spray. In that study, sponsored by the manufacturer of the nasal spray, the latter drug was more effective than the OTFC formulation. ${ }^{59} \mathrm{~A}$ second comparative study is needed before a differentiation in score can be made, however. The other formulations have only been compared with placebo and not with each other. The results of these studies cannot be compared directly, because of differences in applied endpoints, patient population, dosages, fraction of patients with neuropathic pain, response to placebo and baseline BTP intensity (see tables). The criteria for determining successful dosing during the titration phase were different in most studies, which might affect outcomes. The time before study participants were allowed additional breakthrough rescue medication ranged from 10 to $60 \mathrm{~min}$, which might also influence efficacy.

Only one study was performed with the buccal film. ${ }^{71}$ The effects at 15 and $30 \mathrm{~min}$ seem to be less favourable than with the other formulations. This may correlate with a relatively slow absorption, with a tmax of up to 2 hours. The buccal film is awarded $60 \%$ for efficacy. All other formulations are awarded $70 \%$.

In the absence of comparative studies, Zeppetella conducted a network meta-analysis, comparing the different fentanyl formulations. However, owing to the design of this study, it is difficult to draw any firm conclusions. ${ }^{83}$

\section{SIDE EFFECTS}

The incidence and severity of side effects is an important selection criterion. The lower the incidence and severity of observed adverse drug-related events, the higher the score.

\section{Results}

The comparative studies provide limited information on the tolerability and safety of the formulations. In many cases no distinction between the adverse events in both treatment arms is provided and it is not always possible to assess whether adverse events were due to the study medication or to the disease or the maintenance opioids.

All studies were too small scale and of too short a duration to make firm statements about the safety of the formulations.

\section{OTFC versus nasal spray}

One open-label study compared the OTFC tablet and the nasal spray in patients with breakthrough cancer pain. ${ }^{59}$ The total incidence of adverse events was 35\% for OTFC and $46 \%$ for the nasal spray; no statistics were provided to indicate whether this was a significant difference. Adverse events possibly or definitely related to treatment were seen in $19 \%$ of patients with OTFC and in $12 \%$ with the nasal spray. Serious adverse events were seen in $14 \%$ of patients with the nasal spray versus $8 \%$ with the OTFC. None of these serious adverse events was considered to be treatment related. The most common adverse events for both the OTFC and spray formulations were nausea, vomiting, constipation, diarrhoea, dizziness, asthenia, urinary tract infection and pyrexia, with very similar results for both formulations. ${ }^{59}$

\section{Orally disintegrating sublingual tablet}

One phase III study compared the sublingual formulation with placebo. ${ }^{61}$ Patients were titrated in an open-label setting, followed by a double-blind, efficacy phase, lasting 2 weeks, in which the titrated dose was compared with placebo in a crossover study, followed by a 12-month safety study, using openlabel sublingual fentanyl. An overview of the adverse events with the sublingual formulation is provided in table 9. The most frequent side effects were nausea, vomiting, headache and somnolence. During the study period, $31 \%$ of patients experienced side effects that were considered to be possibly or probably treatment related. Eighteen per cent of patients experienced severe adverse events, but only $1 \%$ was considered to be treatment related. ${ }^{61}$

One non-comparative phase IV study enrolled 217 patients with breakthrough cancer pain for an observation period of 28 days. Thirty-three patients (15\%) experienced at least one adverse event during the observation period. Twelve patients (5.5\%) experienced adverse events that were considered to be treatment related. The most frequent events were nausea, fatigue, dizziness and vomiting. ${ }^{80}$ Another non-comparative phase study investigated safety during up to 12 months. Of 139 patients who received at least one dose of the study medication, $84 \%$ experienced at least one adverse event, with the most common adverse events being nausea (23\%), fatigue (15\%) and vomiting (13\%). Thirty-five per cent of the adverse events reported were thought to be possibly or probably related to the study medication. Of the $33 \%$ of serious adverse events reported, none were considered to be related to the study medication. The incidence of withdrawal due to adverse events was $27 \% .^{81}$ 


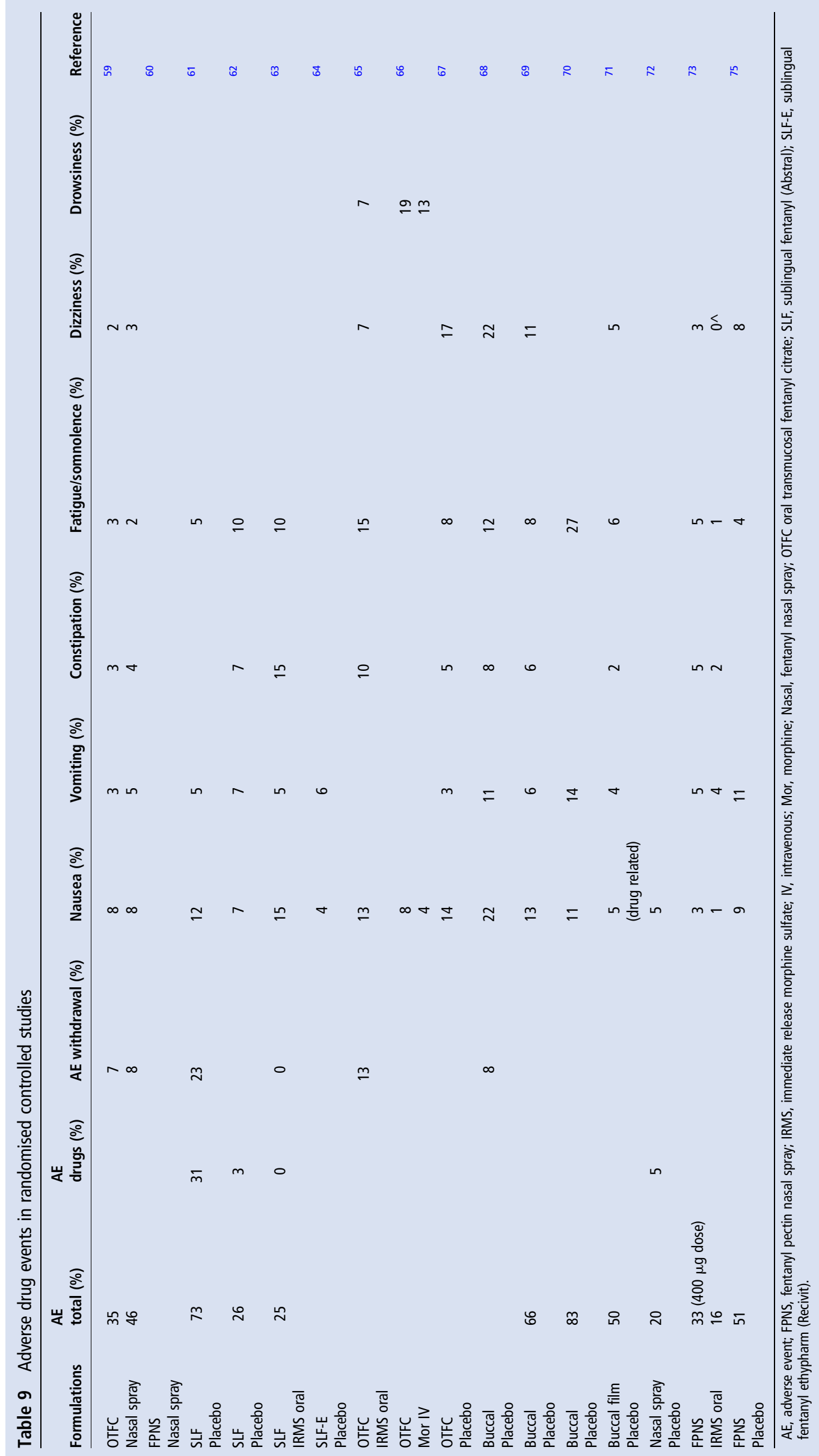




\section{Sublingual tablet}

In one study 77 treatment-emergent adverse events (TEAEs) were reported. However, only 40 (52\%) of these were considered to be directly related to the study treatment. Most were noted to be of mild to moderate severity. The most common TEAEs were typical of opioid administration and included vomiting (5.5\%), nausea (4.4\%), diarrhoea (3.3\%), dry mouth $(3.3 \%)$ and somnolence $(2.2 \%) .{ }^{64}$

\section{OTFC}

An overview of the adverse events with OTFC in clinical studies is provided in table 9. The most common adverse events were dizziness, nausea, vomiting, constipation and somnolence. ${ }^{65-67}$ Only the comparative study between OTFC and IV morphine provided specifications of adverse events in each treatment arm; however, it found that adverse events owing to the treatment were indistinguishable from those resulting from the background opioid analgesia. ${ }^{66}$ One study compared two titration regimens of OTFC, starting with either $200 \mu \mathrm{g}$ or $400 \mu \mathrm{g}$ doses. The side effects seen in this study were considered to be 'possibly', 'probably' or 'almost certainly' related to the study medication and included somnolence (28\%), dizziness (14\%), nausea $(10 \%)$ and headache (5\%). After dose titration and on stabilisation of the dose the incidence of such adverse events reduced by approximately half. ${ }^{82}$

Long-term safety of OTFC was investigated in two studies. A total number of over 38000 episodes of BTP was included in one study. The mean duration of treatment was 91 days (range 1-423 days). Adverse events that were considered to be related to the study medication included somnolence $(9 \%)$, constipation $(8 \%)$, nausea $(8 \%)$, dizziness $(8 \%)$ and vomiting $(5 \%)$. Four per cent of patients withdrew owing to side effects. ${ }^{83}$ Another study investigated OTFC for up to 6 months. In the initial phase, nausea (reported by $14 \%$ of patients) was the most frequent side effect, followed by stomatitis, vomiting and dizziness (7\% each). Ten per cent of patients withdrew owing to side effects. Similar adverse effects were noted in the long-term study up to 6 months but the number of reports was very low. ${ }^{84}$

\section{Buccal tablet}

Two placebo controlled studies made no distinction between active or placebo-treated episodes concerning adverse events. The incidence of adverse events is shown in table 9. Headache was observed in both studies: $15 \%$ and $6 \%$, respectively. Local reactions at the application site were seen in $2 \%$ and $10 \%$ of patients. $^{6869}$

One study provided information on the tolerability of the buccal tablet in a relative large population of 232 patients. The most frequent adverse events were nausea: 37\%, vomiting: 22\%, dizziness: $20 \%$, fatigue: $16 \%$, constipation: $14 \%$,

Table 10 Score for ease of administration

\begin{tabular}{lll}
\hline Formulation & Trade name & Score (\%) \\
\hline Sublingual & Abstral & 100 \\
Sublingual & Recivit & 75 \\
Oromucosal & Actiq & 60 \\
Buccal tablet & Effentora & 85 \\
Buccal film & Breakyl & 85 \\
Nasal spray & Instanyl & 100 \\
Nasal spray & PecFent & 100 \\
\hline
\end{tabular}

anaemia: $14 \%$, headache: $14 \%$, somnolence: $13 \%$, peripheral oedema: $13 \%$, abdominal pain: $11 \%$, dehydration: $11 \%$, anorexia, depression and diarrhoea: 10\% each. Treatment was discontinued by $33 \%$ of study participants owing to adverse events; however, only $31 \%$ of these withdrawals were related to the study medication. The remaining $69 \%$ of withdrawals were attributed to adverse effects associated with the patients underlying disease. Most of the withdrawals occurred during the maintenance phase rather than the titration phase. ${ }^{87}$

One pharmacokinetic study, performed in healthy opioid naïve participants also provided information on tolerability of the buccal tablet at dosages of $600-1300 \mu \mathrm{g}$. Each dose was used in about 100 patients. There was no clear relationship between dose and adverse events, although trends did show that overall fewer adverse events were reported with the 600 and $1000 \mu \mathrm{g}$ dosages $(30 \%$ and $27 \%$ of patients receiving each dose, respectively) than with 1200 and $1300 \mu \mathrm{g}$ doses (43\% and $37 \%$, respectively). No statistics were provided. Dizziness was reported more frequently at the higher dosages (7-11\%) than with the $600 \mu \mathrm{g}$ dose $(1 \%) .{ }^{41}$ The relevance of this study is limited because it was performed in healthy subjects.

One study investigated the long-term (18 months) safety of the buccal tablet in non-cancer pain. During maintenance treatment in a large cohort $(n=646), 11 \%$ of patients withdrew because of adverse events. Other reasons for discontinuation were withdrawal of consent (11\%) and non-compliance (9\%). The observed adverse events were typical of opioids: nausea $(17 \%)$, back pain $(15 \%)$, vomiting $(12 \%)$, headache $(11 \%)$ and constipation $(9 \%) .{ }^{93}$

\section{Buccal film}

In one study TEAEs led to discontinuation of treatment in $14 \%$ of study participants. The most common adverse events leading to discontinuation were nausea and vomiting. Drug-related adverse events were seen in $25 \%$ of patients. $^{71}$

\section{Nasal spray}

One placebo controlled study did not distinguish between active or placebo-treated episodes for adverse events. The incidence of adverse events is shown in table 9. At least one treatment related adverse event was noted in $4.6 \%$ of study participants. Most other adverse events were considered unrelated to drug treatment. Those adverse events resulting from the study treatment were nausea, vomiting and constipation. ${ }^{72}$

\section{FPNS}

One study compared FPNS with IRMS. The incidence of adverse events is shown in table 9. The pattern of adverse events was similar in both groups, but the overall incidence of adverse events was higher in the FPNS group. A greater number of treatment-related adverse events were seen with the higher doses of FPNS than with lower doses. Most common adverse events reported were somnolence, vomiting, dehydration and nausea, and the most serious adverse events were not considered to be related to the study drug. No statistical information was provided in the article. ${ }^{73}$

One study compared FPNS with placebo, and included the incidence of adverse events in the placebo arm of the study. ${ }^{75}$ Adverse events were seen in $51 \%$ of patients with the nasal spray versus and in only 5\% with placebo. Most adverse events were of mild or moderate severity, and increasing the dosage did not increase either the frequency or severity. The incidence of adverse events is shown in table 9. 
The pectin nasal spray was well tolerated in a German study in a population of 225 subjects with BTP in cancer. ${ }^{94}$

A further study investigated the medium-term (16 weeks) safety of the FPNS. During maintenance treatment in a large cohort ( $n=356$, of whom 110 completed the 16 week period), adverse events were seen in $25 \%$ of patients. These were reported as mild to moderate in severity, and most commonly included dizziness $(5.2 \%)$, vomiting (3.7\%), constipation and somnolence (both 3.5\%). The number of patients reporting one adverse event was higher after administration of an $800 \mu \mathrm{g}$ dose (20.1\%) than with lower doses $(11.2 \%, 9.5 \%$ and $13.4 \%$ with 100,200 and $400 \mu \mathrm{g}$ doses, respectively). ${ }^{89}$

The number of comparative studies is disappointingly limited, which makes it difficult to judge the relative safety and tolerability of different fentanyl formulations. Only one open-label randomised study was performed: between OTFC and the nasal spray. In this study, sponsored by the manufacturer of the nasal spray, no difference in the incidence of side effects was seen. ${ }^{59}$ The other formulations have only been compared with placebo and not with each other, but the adverse events seem to be similar for all formulations.

All formulations are awarded 60\%.

\section{DOSAGE FREQUENCY/EASE OF ADMINISTRATION}

All formulations may be administered up to four times daily. If more frequent administration is necessary, adjustment of maintenance dosages or selection of opioids is necessary. There are no differences between the fentanyl formulations in this respect.

The number of dosages per breakthrough event is one or two for each formulation. Again, there are no differences between the formulations in this respect. This is, however, the case in a limited number of patients and was scored under Formulations. One study compared the OTFC formulation and the nasal spray in patients with breakthrough cancer pain and considered ease of use and patient preference as part of its outcomes. A marked difference was seen in patient preference, with over $60 \%$ of patients considering the nasal formulation very easy to use, compared with $11 \%$ for the OTFC formulation. A description of very easy or easy to use was given by $90 \%$ of patients for the nasal spray and $40 \%$ for the OTFC formulation. ${ }^{59}$ It must be remembered that the study was sponsored by the manufacturer of the nasal spray. Patient information and counselling are key factors in a patient's opinion of the ease of use, and these procedures were not described in any detail in this study. The results of this study need to be confirmed in other, independent, studies before conclusions can be drawn.

Differences in the application of OTFC may, however, affect its efficacy. The absorption may be reduced in patients with a dry mouth and it may be troublesome to apply the product for $15 \mathrm{~min}$ or longer. Shorter application may affect efficacy and safety as more of the product may be swallowed rather than absorbed via oral mucosa.

The nasal spray should be used in an upright position, which usually means no major problem for bedridden patients. In cases of rhinitis, the nose should be emptied immediate before the spray is used.

No studies have described the acceptance of buccal tablets. However, two of the authors who prescribed buccal tablets reported that a significant proportion of patients experience an unpleasant taste and problems with having the tablet in the mouth for å longer period. Although not documented in any studies, this is taken into account when scores were considered. The buccal formulations score is $15 \%$ lower.
We found one relevant study that studied the practical aspects of the various formulations of fentanyl in BTP. The study was not sponsored by any company. The investigators studied placebo formulations (supplied by the manufacturers) of an orally disintegrating sublingual tablet, a buccal tablet and a nasal spray and these were compared with the medication that the 30 patients with cancer were using (oral solution or tablets of morphine $^{21}$ or oxycodone. ${ }^{7}$ One patient was receiving subcutaneous morphine). The formulations were judged on accessibility (ease with which a dose could be obtained from its container), administration, palatability (based on taste and other sensations), overall satisfaction (efficacy and tolerability; studies for the usual medication only, because the other formulations were supplied as placebo) and overall impression. ${ }^{95}$ For accessibility, no differences were seen between the disintegrating sublingual and buccal tablet, but both formulations were judged significantly better than the nasal spray. For ease of administration, the disintegrating sublingual tablet performed significantly better than the buccal tablet $(p=0.04)$, but the difference with the nasal spray was just statistically significant $(p=0.05)$. In particular, the quicker dissolution of the sublingual tablet was considered advantageous. The sublingual tablet also performed better than the other formulations for palatability $(p<0.01)$. It should be noted that placebo formulations were used and therefore the results are not by definition also valid for the fentanyl formulations. This resulted in a better overall acceptability for the sublingual placebo tablet than for the buccal tablet $(p<0.01)$ and nasal spray $(p=0.04),{ }^{95}$ which complies well with the results from the SOJA score.

One of the authors commented that opening of the original package of FPNS is difficult for many patients and that the sublingual formulations are very small and difficult to handle for patients with arthritic or shaking hands.

The sublingual tablet (Recivit) must be kept under the tongue for $30 \mathrm{~min}$. The fentanyl in the sublingual tablet is not incorporated throughout the tablet, but in the outer layer, allowing rapid dissolution of fentanyl, whereas the neutral core dissolves more slowly. ${ }^{96}$ Although this formulation has been very recently introduced and no patient data are available, the same argument is valid as for the buccal tablet; this formulation scores $25 \%$ lower. Scoring of the formulations is shown in table 10 .

\section{DOCUMENTATION}

The score for this criterion was divided over four subcriteria.

The first two subcriteria are indicative of the overall clinical documentation of the drugs in randomised controlled clinical studies. A large number of clinical studies and a large number of patients included in these studies provide confidence in the clinical efficacy and safety of this drug in the studied population. The third and fourth criteria are indicative of the overall clinical experience with the drug. These subcriteria may introduce a bias to the advantage of older drugs. The safety of a newly introduced drug cannot be guaranteed since there are a limited number of clinical studies and relatively small number of patients. Patients most at risk of adverse events (eg, those with renal impairment) are usually excluded from trials. Both the number of patients who have been treated worldwide and the period that a certain drug has been available are important, as it may take time until adverse reactions occur.

\section{Number of comparative studies}

The number of randomised comparative clinical studies with rapid-acting fentanyl formulations is an important determinant of the clinical documentation. 
Table 11 Documentation of the different formulations

\begin{tabular}{|c|c|c|c|c|c|c|c|}
\hline Formulation & Trade name & Number of studies & Number of patients & Number of years on the market & Patient-days experience & Reference & Score $(\%)$ \\
\hline Sublingual & Abstral & 3 & 123 & $>10$ & $>100$ & $61-63$ & 57 \\
\hline Sublingual & Recivit & 1 & 76 & $>10$ & $>100$ & 64 & 53 \\
\hline Oromucosal & Actiq & 4 & 296 & $>10$ & $>100$ & $59,65-67$ & 62 \\
\hline Buccal tablet & Effentora & 3 & 237 & $>10$ & $>100$ & $68-70$ & 60 \\
\hline Buccal film & Breakyl & 1 & 82 & $>10$ & $>100$ & 71 & 53 \\
\hline Nasal spray & Instanyl & 3 & 235 & $>10$ & $>100$ & $59,60,72$ & 60 \\
\hline Nasal spray & PecFent & 4 & 283 & $>10$ & $>100$ & $60,73-75$ & 62 \\
\hline
\end{tabular}

Five per cent of the relative weight for this subcriterion was awarded for each double-blind comparative study. A formulation is awarded $100 \%$ when 20 studies are available.

2. Number of patients in these studies

Besides the number of clinical studies, the number of patients who have been treated with the drug in question must also be taken into consideration.

One per cent of the relative weight for this subcriterion was awarded for every 10 patients enrolled in double-blind comparative studies. A formulation is awarded $100 \%$ when over 1000 patients are included.

3. Number of years marketed

The number of years that a product has been marketed in any country in the world provides information on the clinical experience with the drug. If a product is on the market for more than 10 years it is very unlikely that serious adverse reactions will be observed that have not been seen in the first 10 years after its introduction.

Ten per cent of the relative weight for this subcriterion was awarded for every year that the product has been available on the market.

4. Number of patient-days worldwide

Besides the number of years that a product is on the market, the number of patient-days experience with the drug also plays a role.

One per cent of the relative weight for this subcriterion was awarded for every million patient days worldwide.

The results for the different formulations are summarised in table 11.

\section{Results}

The number of evaluable patients in the study by Thronæs et $a l^{78}$ (23 patients) was too low to include this study in the documentation assessment.
There is extensive clinical experience with the molecule fentanyl. It is highly unlikely that new serious adverse events will be reported using the formulations included in this analysis. Therefore, all formulations were assigned the full score for years on the market and patient-days experience.

\section{SOJA score}

The SOJA score is presented in table 12.

\section{DISCUSSION}

The evaluation of the criteria by the SOJA method is highly standardised in order to promote unbiased judgement of drugs from various pharmacological categories based on clinically relevant criteria. Of course, there is debate about the correct scoring system for each criterion and individual decisions are highly subjective. This is the case with any method used to quantify the properties of drugs. The SOJA method is intended as a tool for rational drug decision-making, enabling clinicians and pharmacists to include all relevant aspects of a certain group of drugs, thereby preventing formulary decisions being based on only one or two criteria. Additionally, possible 'hidden criteria' (such as personal financial interest) are excluded from the decision-making process. The outcome of this study should be seen as the basis for discussions within formulary committees and not as the absolute truth.

Acquisition cost was not included as a selection criterion to make the score internationally applicable. The present matrix can be used as a preselection tool of the most suitable formulations from a quality point of view. Because prices may differ between institutions and different healthcare systems, individual procurement procedures should lead to a selection of the best formulations.

There is some overlap between the applied selection criteria. The number of available formulations is related to dosage

Table 12 Score and ranking

\begin{tabular}{|c|c|c|c|c|c|c|c|c|c|}
\hline & & Strengths & Bioavailability & Interactions & Efficacy & Side effects & Ease of use & Documentation & Tota \\
\hline RWF & & 60 & 50 & 50 & 350 & 150 & 140 & 200 & 1000 \\
\hline Formulation & Trade name & & & & & & & & \\
\hline Sublingual & Abstral & 60 & 34 & 40 & 245 & 90 & 140 & 114 & 723 \\
\hline Sublingual & Recivit & 54 & 33 & 40 & 245 & 90 & 105 & 106 & 673 \\
\hline Oromucosal & Actiq & 48 & 26 & 40 & 245 & 90 & 84 & 125 & 658 \\
\hline Buccal tablet & Effentora & 54 & 30 & 40 & 245 & 90 & 119 & 120 & 698 \\
\hline Buccal film & Breakyl & 48 & 34 & 40 & 210 & 90 & 119 & 106 & 647 \\
\hline Nasal spray & Instanyl & 42 & 33 & 40 & 245 & 90 & 140 & 120 & 710 \\
\hline Nasal spray & PecFent & 36 & 30 & 40 & 245 & 90 & 140 & 124 & 705 \\
\hline
\end{tabular}


frequency. If fewer formulations are available, it may be necessary to apply two dosages instead of one. On the other hand, a large number of strengths allow minor dose increases instead of doubling the dose, because few strengths are available. This may also reduce cost (or maybe side effects) during the titration period. This was taken into account in the criterion available formulations and not in acquisition cost.

The onset of action is a relevant selection criterion. We have, however, not included this in the set of criteria, because there were insufficient direct comparative data to make a good estimation of the rate of action of the various formulations of fentanyl. For this reason we chose variability in the rate of absorption as a pharmacokinetic criterion.

There is limited evidence that the fentanyl formulations act more quickly than immediate release morphine or oxycodone. Their pharmacokinetics are obviously more favourable, but only three studies have compared a fentanyl formulation with immediate release morphine. One study compared OTFC with oral morphine and a (slightly, but significantly) better clinical efficacy was found for OTFC at all time points between 15 and 60 min. ${ }^{65}$ Another study compared FPNS with morphine. The nasal spray performed better than morphine at $15 \mathrm{~min}$ or later, but the absolute differences were limited (0.2-0.5 points difference in PID). ${ }^{73}$ In both studies all patients entered a titration phase with fentanyl before the start of the study. Only patients showing successful titration with fentanyl entered the study, which might have led to a selection bias compared with morphine. The sublingual tablet was more effective than morphine immediate release in a small-scale study. ${ }^{63}$ In that study, morphine was used in the titration phase of the patients randomised to morphine. OTFC was, however, less effective as IV morphine. ${ }^{66}$ A meta-analysis concluded that fentanyl formulations showed better clinical efficacy than placebo, while no superiority versus placebo could be demonstrated for morphine. ${ }^{97}$

Cancer BTP is a heterogeneous syndrome which deserves thorough analysis by the physician. It requires continuous patient education and support on how to deal with various types and characteristics of BTP using both pharmacological and non-pharmacological treatments. Many of the studies referenced in this manuscript do not specify the type and characteristics of BTP in detail and correlations between BTP and response or non-response to the drugs are not investigated. In addition several of these studies have different outcomes.

The intensity of breakthrough episodes may alter with time, which complicates optimal treatment. The recently published European Society of Medical Oncology guideline for BTP in cancer states that rapidly acting fentanyl formulations have many advantages which suit the profile of unpredictable BTP in cancer. Immediate release oral opioids can be used in predictable BTP, such as washing or changing clothes. ${ }^{93}$ It should be kept in mind that the huge diversity of BTP affects the choice of the 'optimal medicine'.

The acquisition cost of all fentanyl formulations included in this analysis is relative large, especially compared with immediate release morphine or oxycodone, which are often used in the treatment of BTP. This should be taken into consideration before selecting a fentanyl formulation. The large difference in cost was the main reason why the UK National Institute of Health and Care Excellence (NICE) recommended immediate release morphine as first choice for the treatment of BTP rather than rapid acting fentanyl products. ${ }^{8}$

Some interesting differences in score between the formulations are seen. Of course, the scoring presented here is based on the weights assigned by the authors. The essence of the SOJA method is that users of the method may assign their own relative weight to each selection criterion. This interactive programme is available on the internet at tablet.sojaonline.nl. Other relative weights will of course affect the relative scores for the formulations. With scarcely any comparative studies available, it is not possible to reliably evaluate the formulations on the most important selection criteria, clinical efficacy and safety.

With these limitations in mind, the sublingual formulations show higher scores than the other formulations. Because no independent studies were performed concerning patient preference for all the available formulations, there is a clear need to involve patients in the selection process of immediate acting fentanyl formulations. Patient education about the heterogeneity of BTP is essential. The preference of the patient for the various available formulations is highly relevant, also taking into consideration the specific situation of the patient (common cold and nasal spray as well as dry mouth or stomatitis for the buccal and sublingual formulations). No independent studies have investigated patient preference for any of the formulations and patients need to be well informed about their pros and cons. Because there are no known differences in clinical efficacy or safety, patient preference should be a very important selection criterion. The OTFC formulation seems less patient-friendly than other formulations, but this needs verification in more comparative (and independent) studies. It is doubtful whether such studies will ever be performed.

\section{Author affiliations}

${ }^{1}$ Department of Clinical Pharmacy and Toxicology, Zuyderland Medical Centre, Sittard, The Netherlands

${ }^{2}$ Palliative Care MUMC+, Maastricht, The Netherlands

${ }^{3}$ Tjongerschans Hospital, Heerenveen, The Netherlands

${ }^{4}$ IFNAP Institute for Neurosciences, Algesiology and Paediatrics, Nürnberg, Germany

${ }^{5}$ University of Nottingham, Nottingham, UK

${ }^{6}$ Nottingham University Hospitals NHS Trust, Nottingham, UK

${ }^{7}$ Antrim Area Hospital, Antrim, UK

${ }^{8}$ Faculty of Medicine, Department of Cancer Research and Molecular Medicine,

European Palliative Care Research Centre (PRC), Norwegian University of Science and Technology (NTNU) and St Olavs Hospital, Trondheim University Hospital, Trondheim, Norway

Contributors The manuscript was written by the first author. All other authors have commented extensively on the manuscript.

Competing interests None declared.

Provenance and peer review Not commissioned; externally peer reviewed.

Open Access This is an Open Access article distributed in accordance with the Creative Commons Attribution Non Commercial (CC BY-NC 4.0) license, which permits others to distribute, remix, adapt, build upon this work non-commercially, and license their derivative works on different terms, provided the original work is properly cited and the use is non-commercial. See: http://creativecommons.org/ licenses/by-nc/4.0/

\section{REFERENCES}

1 Goudas LC, Bloch R, Gialeli-Goudas M, et al. The epidemiology of cancer pain. Cancer Invest 2005:23:182-90.

2 Strömgren AS, Sjogren P, Goldschmidt D, et al. Symptom priority and course of symptomatology in specialized palliative care. J Pain Symptom Manage 2006;31:199-206.

3 van den Beuken-van Everdingen MH, de Rijke JM, Kessels AG, et al. Prevalence of pain in patients with cancer: a systematic review of the past 40 years. Ann Oncol 2007; 18:1437-49.

4 Caraceni A, Hanks G, Kaasa S, et al. European palliative care research collaborative (EPCRC); European association for palliative care (EAPC). Use of opioid analgesics in the treatment of cancer pain: evidence-based recommendations from the EAPC. Lancet Oncol 2012;13:e58-68.

5 Portenoy RK, Hagen NA. Breakthrough pain: definition, prevalence and characteristics. Pain 1990;41:273-81.

6 Haugen DF, Hjermstad MJ, Hagen N, et al. European palliative care research collaborative (EPCRC). Assessment and classification of cancer breakthrough pain: a systematic literature review. Pain 2010;149:476-82. 
7 Davies AN, Dickman A, Reid C, et al. The management of cancer-related breakthrough pain: recommendations of a task group of the Science Committee of the Association for Palliative Medicine of Great Britain and Ireland. Eur I Pain 2009:13:331-8.

8 National Institute for Health and Care Excellence. Clinical Guideline CG140 Opioids in palliative care: safe and effective prescribing of strong opioids for pain in palliative care of adults. May 2012.

9 Davies A, Buchanan A, Zeppetella G, et al. Breakthrough cancer pain: an observational study of 1000 European oncology patients. J Pain Symptom Manage 2013:46:619-28

10 Deandrea S, Corli O, Consonni D, et al. Prevalence of breakthrough cancer pain: a systematic review and a pooled analysis of published literature. J Pain Symptom Manage 2014:47:57-76.

11 Zeppetella G, O'Doherty CA, Collins S. Prevalence and characteristics of breakthrough pain in cancer patients admitted to a hospice. I Pain Symptom Manage 2000;20:87-92.

12 Caraceni A, Martini C, Zecca E, et al. Breakthrough pain characteristics and syndromes in patients with cancer pain. An international survey. Palliat Med 2004;18:177-83.

13 Elsner F, Zeppetella G, Porta-Sales J, et al. Newer generation fentanyl transmucosal products for breakthrough pain in opioid-tolerant cancer patients. Clin Drug Invest 2011:31:605-18.

14 Janknegt $R$, Steenhoek A. The system of objectified judgement analysis. A tool in rational drug selection for formulary purposes. Drugs 1997;53: $550-62$.

15 Summary of Product Characteristics Abstral. https://www.medicines.org.uk/emcl medicine/21371 (accessed 4 Oct 2016).

16 Summary of Product Characteristics Recivit. https:// http://www.medicines.org.uk/ emc/medicine/28821 (accessed 4 Oct 2016).

17 Summary of Product Characteristics Actiq. https:// http://www.medicines.org.uk/emc medicine/30547 (accessed 4 Oct 2016).

18 Summary of Product Characteristics Effentora. https:// http://www.medicines.org.uk/ emc/medicine/28907 (accessed 4 Oct 2016).

19 Summary of Product Characteristics Breakyl. https:// http://www.medicines.org.uk/ emc/medicine/28361 (accessed 4 Oct 2016).

20 Summary of Product Characteristics Instanyl. https:// http://www.medicines.org.uk/ emc/medicine/22242 (accessed 4 Oct 2016).

21 Summary of Product Characteristics PecFent. https:// http://www.medicines.org.uk/ emc/medicine/23962 (accessed 4 Oct 2016).

22 Davies $A$, Mundin $G$, Vriens J, et al. The influence of low salivary flow rates on the absorption of a sublingual fentanyl citrate formulation for breakthrough cancer pain J Pain Symptom Manage 2016;51:538-45.

23 Darwish $M$, Kirby $M$, Robertson $P$, et al. Absorption of fentanyl from fentanyl buccal tablet in cancer patients with or without oral mucositis: a pilot study. Clin Drug Investig 2007;27:605-11.

24 Davies A, Finn A, Tagarro I. Intra- and interindividual variabilities in the pharmacokinetics of fentanyl buccal soluble film in healthy subjects: a cross-study analysis. Clin Drug Investig 2011:31:317-24.

25 Darwish M, Tempero K, Jiang JG, et al. Relative bioavailability of fentanyl following various dosing regimens of fentanyl buccal tablet in healthy Japanese volunteers. Arch Drug Inf 2008;1:56-62.

26 Darwish M, Tempero K, Jiang JG, et al. Dose proportionality of fentanyl buccal tablet in healthy Japanese volunteers. Arch Drug Inf 2008;1:43-9.

27 Darwish M, Tempero K, Jiang JG, et al. Extent of fentanyl accumulation following multiple doses of fentanyl buccal tablet 400 microg in healthy Japanese volunteers. Arch Drug Inf 2008; 1:50-5.

28 Darwish M, Kirby M, Robertson P Jr, et al. Absolute and relative bioavailability of fentanyl buccal tablet and oral transmucosal fentanyl citrate. J Clin Pharmacol 2007:47:343-50

29 Pather SI, Siebert JM, Hontz J. Enhanced buccal delivery of entanyl using the OraVescent drug delivery system. Drug Delivery Technol 2001;1:54-7.

30 Thronæs M, Kaasa S, Dale O. A pilot study of nasal fentanyl for patient controlled treatment of cancer pain. J Opioid Manag 2014:10:21-8.

31 Lister N, Warrington S, Boyce M, et al. Pharmacokinetics, safety, and tolerability of ascending doses of sublingual fentanyl, with and without naltrexone, in Japanese subjects. J Clin Pharmacol 2011:51:1195-204.

32 Lennernäs $B$, Hedner $T$, Holmberg $M$, et al. Pharmacokinetics and tolerability of different doses of fentanyl following sublingual administration of a rapidly dissolving tablet to cancer patients: a new approach to treatment of incident pain. Br J Clin Pharmacol 2005:59:249-53.

33 Parikh N, Goskonda V, Chavan A, et al. Single-dose pharmacokinetics of fentanyl sublingual spray and oral transmucosal fentanyl citrate in healthy volunteers: a randomized crossover study. Clin Ther 2013:35:236-43.

34 Streisand JB, Busch MA, Egan TD, et al. Dose proportionality and pharmacokinetics of oral transmucosal fentanyl citrate. Anesthesiology 1998;88:305-9.

35 Kharasch ED, Hoffer C, Whittington D. Influence of age on the pharmacokinetics and pharmacodynamics of oral transmucosal fentanyl citrate. Anesthesiology 2004;101:738-43.
36 Vasisht N, Gever LN, Tagarro I, et al. Formulation selection and pharmacokinetic comparison of fentanyl buccal soluble film with oral transmucosal fentanyl citrate: a randomized, open-label, single-dose, crossover study. Clin Drug Investig 2009:29:647-54.

37 Darwish M, Kirby M, Robertson P Jr, et al. Pharmacokinetic properties of fentanyl effervescent buccal tablets: a phase I, open-label, crossover study of single-dose $100,200,400$, and $800 \mu \mathrm{g}$ in healthy adult volunteers. Clin Ther 2006:28:707-14.

38 Darwish M, Tempero K, Kirby M, et al. Pharmacokinetics and dose proportionality of fentanyl effervescent buccal tablets in healthy volunteers. Clin Pharmacokinet 2005:44:1279-86.

39 Darwish M, Kirby M, Robertson P Jr, et al. Comparison of equivalent doses of fentanyl buccal tablets and arteriovenous differences in fentanyl pharmacokinetics. Clin Pharmacokinet 2006;45:843-50.

40 Darwish M, Tempero K, Kirby M, et al. Relative bioavailability of the fentanyl effervescent buccal tablet (FEBT) $1080 \mathrm{pg}$ versus oral transmucosal fentanyl citrate $1600 \mathrm{pg}$ and dose proportionality of FEBT 270 to $1300 \mu \mathrm{g}$ : a single-dose, randomized, open-label, three-period study in healthy adult volunteers. Clin Ther 2006:28:715-24.

41 Darwish M, Kirby M, Robertson P Jr, et al. Dose proportionality of fentanyl buccal tablet in doses ranging from 600 to $1300 \mu \mathrm{g}$ in healthy adult subjects: a randomized, open-label, four-period, cros over, single-centre study. Clin Drug Investig 2010;30:365-73.

42 Darwish $\mathrm{M}$, Kirby $\mathrm{M}$, Jiang JG, et al. Bioequivalence following buccal and sublingual placement of fentanyl buccal tablet $400 \mu \mathrm{g}$ in healthy subjects. Clin Drug Investig 2008;28:1-7.

43 Darwish M, Kirby M, Robertson P Jr, et al. Single-dose and steady-state pharmacokinetics of fentanyl buccal tablet in healthy volunteers. J Clin Pharmacol 2007:47:56-63

44 Finn AL, Vasisht N, Stark JG, et al. Dose proportionality and pharmacokinetics of fentanyl buccal soluble film in healthy subjects: a phase I, open-label, three-period, crossover study. Clin Drug Investig 2012;32:63-71.

45 Vasisht N, Gever LN, Tagarro I, et al. Evaluation of the single- and multiple-dose pharmacokinetics of fentanyl buccal soluble film in normal healthy volunteers. J Clin Pharmacol 2010;50:785-91.

46 Nave R, Connolly SM, Popper L, et al. Single-dose and multi-dose delivery systems for intranasal fentanyl spray are bioequivalent as demonstrated in a replicate pharmacokinetic study. Int I Clin Pharmacol Ther 2012;50:751-9.

47 Plock N, Facius A, Hartmann L, et al. An innovative phase I population pharmacokinetic approach to investigate the pharmacokinetics of an intranasal fentanyl spray in healthy subjects. Int I Clin Pharmacol Ther 2013;51:495-508.

48 Kaasa S, Moksnes K, Nolte T, et al. Pharmacokinetics of intranasal fentanyl spray in patients with cancer and breakthrough pain. J Opioid Manag 2010;6:17-26.

49 Fisher A, Watling $M$, Smith $A$, et al. Pharmacokinetics and relative bioavailability of fentanyl pectin nasal spray 100-800 mcg in healthy volunteers. Int I Clin Pharmacol Ther 2010;48:860-7.

50 Fisher A, Watling $M$, Smith $A$, et al. Pharmacokinetic comparisons of three nasal fentanyl formulations; pectin, chitosan and chitosan-poloxamer 188. Int I Clin Pharmacol Ther 2010;48:138-45.

51 Kharasch ED, Whittington D, Hoffer C. Influence of hepatic and intestinal cytochrome P4503A activity on the acute disposition and effects of oral transmucosal fentanyl citrate. Anesthesiology 2004;101:729-37.

52 Mercadante S, Ferrera P, Arcuri E. The use of fentanyl buccal tablets as breakthrough medication in patients receiving chronic methadone therapy: an open label preliminary study. Support Care Cancer 2011;19:435-8.

53 Mercadante S, Ferrera P, Adile C, et al. Fentanyl buccal tablets for breakthrough pain in highly tolerant cancer patients: preliminary data on the proportionality between breakthrough pain dose and background dose. J Pain Symptom Manage 2011:42:464-9.

54 Zeppetella G. An assessment of the safety, efficacy, and acceptability of intranasal fentanyl citrate in the management of cancer-related breakthrough pain: a pilot study. J Pain Symptom Manage 2000;20:253-8.

55 Loitman JE. Transmucosal fentanyl in ovarian cancer. J Pain Symptom Manage 2002:23:5-7.

56 Zeppetella G. Nebulized and intranasal fentanyl in the management of cancer-related breakthrough pain. Palliat Med 2000;14:57-8.

57 Farrar JT, Portenoy RK, Berlin JA, et al. Defining the clinically important difference in pain outcome measures. Pain 2000;88:287-94.

58 Farrar JT, Pritchett YL, Robinson M, et al. The clinical importance of changes in the 0 to 10 numeric rating scale for worst, least, and average pain intensity: analyses of data from clinical trials of duloxetine in pain disorders. J Pain 2010;11:109-18.

59 Mercadante S, Radbruch L, Davies A, et al. A comparison of intranasal fentanyl spray with oral transmucosal fentanyl citrate for the treatment of breakthrough cancer pain: an open-label, randomised, crossover trial. Curr Med Res Opin 2009:25:2805-15.

60 Mercadante S, Prestia G, Adile C, et al. Intranasal fentanyl (INFS) versus fentanyl pectin nasal spray (FPNS) for the management breakthrough cancer pain in doses proportional to basal opioid regimen. J Pain 2014;15:602-7. 
61 Rauck RL, Tark M, Reyes E, et al. Efficacy and long-term tolerability of sublingual fentanyl orally disintegrating tablet in the treatment of breakthrough cancer pain. Curr Med Res Opin 2009;25:2877-85.

62 Shimoyama N, Gomyo I, Katakami N, et al. Efficacy and safety of sublingual fentanyl orally disintegrating tablet at doses determined by titration for the treatment of breakthrough pain in Japanese cancer patients: a multicenter, randomized, placebo-controlled, double-blind phase III trial. Int J Clin Oncol 2015;20:198-206.

63 Velazquez Rivera I, Munoz Garrido JC, Garcia Velasco P, et al. Efficacy of sublingua fentanyl vs oral morphine for cancer-related breakthrough pain. Adv Ther 2014;31:107-17.

64 Novotna S, Valentova K, Fricova J, et al. A randomized, placebo-controlled study of a new sublingual formulation of fentanyl citrate (fentanyl ethypharm) for breakthrough pain in opioid-treated patients with cancer. Clin Ther 2014;36:357-67.

65 Coluzzi PH, Schwartzberg L, Conroy JD, et al. Breakthrough cancer pain: a randomized trial comparing oral transmucosal fentanyl citrate (OTFC) and morphine sulfate immediate release (MSIR). Pain 2001;91:123-30.

66 Mercadante $S$, Villari P, Ferrera $P$, et al. Transmucosal fentanyl vs intravenous morphine in doses proportional to basal opioid regimen for episodic-breakthrough pain. Br J Cancer 2007;96:1828-33.

67 Farrar JT, Cleary J, Rauck R, et al. Oral transmucosal fentanyl citrate: randomized, double-blinded, placebo-controlled trial for treatment of breakthrough pain in cancer patients. J Natl Cancer Inst 1998;90:611-16.

68 Portenoy RK, Taylor D, Messina J, et al. A randomized, placebo-controlled study of fentanyl buccal tablet for breakthrough pain in opioid-treated patients with cancer. Clin J Pain 2006;22:805-11.

69 Slatkin NE, Xie F, Messina J, et al. Fentanyl buccal tablet for relief of breakthrough pain in opioid-tolerant patients with cancer-related chronic pain. J Support Oncol 2007;5:327-34.

70 Kosugi T, Hamada S, Takigawa C, et al. A randomized, double-blind, placebo-controlled study of fentanyl buccal tablets for breakthrough pain: efficacy and safety in Japanese cancer patients. J Pain Symptom Manage 2014:47:990-1000.

71 Rauck R, North J, Gever LN, et al. Fentanyl buccal soluble film (FBSF) for breakthrough pain in patients with cancer: a randomized, double-blind, placebo-controlled study. Ann Oncol 2010;21:1308-14.

72 Kress HG, Orońska A, Kaczmarek Z, et al. Efficacy and tolerability of intranasal fentanyl spray 50 to 200 microg for breakthrough pain in patients with cancer: a phase III, multinational, randomized, double-blind, placebo-controlled, crossover trial with a 10-month, open-label extension treatment period. Clin Ther 2009;31:1177-91.

73 Fallon M, Reale C, Davies A, et al. Efficacy and safety of fentanyl pectin nasal spray compared with immediate-release morphine sulfate tablets in the treatment of breakthrough cancer pain: a multicenter, randomized, controlled, double-blind, double-dummy multiple-crossover study. J Support Oncol 2011;9:224-31.

74 Mercadante S, Aielli F, Adile C, et al. Fentanyl pectin nasal spray versus oral morphine in doses proportional to the basal opioid regimen for the management of breakthrough cancer pain: a comparative study. J Pain Symptom Manage 2016;52:27-34.

75 Portenoy RK, Burton AW, Gabrail N, et al. A multicenter, placebo-controlled, double-blind, multiple-crossover study of Fentanyl Pectin Nasal Spray (FPNS) in the treatment of breakthrough cancer pain. Pain 2010;151:617-24.

76 Davies A, Sitte T, Elsner F, et al. Consistency of efficacy, patient acceptability, and nasal tolerability of fentanyl pectin nasal spray compared with immediate-release morphine sulfate in breakthrough cancer pain. J Pain Symptom Manage 2011:41:358-66.

77 Lennernäs B, Frank-Lissbrant I, Lennernäs $\mathrm{H}$, et al. Sublingual administration of fentanyl to cancer patients is an effective treatment for breakthrough pain: results from a randomized phase II study. Palliat Med 2010;24:286-93.
78 Thronæs M, Popper L, Eeg M, et al. Efficacy and tolerability of intranasal fentanyl spray in cancer patients with breakthrough pain. Clin Ther 2015;37: 585-96.

79 Taylor D, Galan V, Weinstein SM, et al. Fentanyl pectin nasal spray in breakthrough cancer pain. J Support Oncol 2010;8:184-90.

80 Überall MA, Müller-Schwefe GH. Sublingual fentanyl orally disintegrating tablet in daily practice: efficacy, safety and tolerability in patients with breakthrough cancer pain. Curr Med Res Opin 2011;27:1385-94.

81 Nalamachu S, Hassman D, Wallace MS, et al. Long-term effectiveness and tolerability of sublingual fentanyl orally disintegrating tablet for the treatment of breakthrough cancer pain. Curr Med Res Opin 2011;27:519-30.

82 Portenoy RK, Payne R, Coluzzi P, et al. Oral transmucosal fentanyl citrate (OTFC) for the treatment of breakthrough pain in cancer patients: a controlled dose titration study. Pain 1999;79:303-12.

83 Payne R, Coluzzi P, Hart L, et al. Long-term safety of oral transmucosal fentanyl citrate for breakthrough cancer pain. J Pain Symptom Manage 2001;22: 575-83.

84 Hanks GW, Nugent M, Higgs CM, et al. Oral transmucosal fentanyl citrate in the management of breakthrough pain in cancer: an open, multicentre, dose-titration and long-term use study. Palliat Med 2004;18:698-704.

85 Taylor DR, Webster LR, Chun SY, et al. Impact of breakthrough pain on quality of life in patients with chronic, noncancer pain: patient perceptions and effect of treatment with oral transmucosal fentanyl citrate (OTFC, ACTIQ). Pain Med 2007:8:281-8.

86 Christie JM, Simmonds M, Patt R, et al. Dose-titration, multicenter study of oral transmucosal fentanyl citrate for the treatment of breakthrough pain in cancer patients using transdermal fentanyl for persistent pain. J Clin Oncol 1998;16:3238-45.

87 Weinstein SM, Messina J, Xie F. Fentanyl buccal tablet for the treatment of breakthrough pain in opioid-tolerant patients with chronic cancer pain: a long-term, open-label safety study. Cancer 2009;115:2571-9.

88 Mercadante $S$, Gatti A, Porzio G, et al. Dosing fentanyl buccal tablet for breakthrough cancer pain: dose titration versus proportional doses. Curr Med Res Opin 2012;28:963-8.

89 Kleeberg UR, Filbet M, Zeppetella G. Fentanyl buccal tablet for breakthrough cancer pain: why titrate? Pain Pract 2011;11:185-90.

90 Mercadante S, Porzio G, Aielli F, et al. The use of fentanyl buccal tablets for breakthrough pain by using doses proportional to opioid basal regimen in a home care setting. Support Care Cancer 2013;21:2335-9.

91 Veldhorst-Janssen NM, Fiddelers AA, Zandstra $\mathrm{H}$, et al. Patient satisfaction with intranasal fentanyl for breakthrough pain. J Palliat Med 2012;15:631-2.

92 Zeppetella G, Messina J, Xie F, et al. Consistent and clinically relevant effects with fentanyl buccal tablet in the treatment of patients receiving maintenance opioid therapy and experiencing cancer-related breakthrough pain. Pain Pract 2010;10:287-93.

93 Fine PG, Messina J, Xie F, et al. Long-term safety and tolerability of fentanyl buccal tablet for the treatment of breakthrough pain in opioid-tolerant patients with chronic pain: an 18-month study. J Pain Symptom Manage 2010;40:747-60.

94 Ueberall MA, Lorenzl S, Lux EA, et al. Efficacy, safety, and tolerability of fentanyl pectin nasal spray in patients with breakthrough cancer pain. J Pain Res 2016;9:571-85

95 England R, Maddocks M, Manderson C, et al. How practical are transmucosal fentanyl products for breakthrough cancer pain? Novel use of placebo formulations to survey user opinion. BMJ Support Palliat Care 2011;1:349-51.

96 Davies A. A new fast-acting sublingual fentanyl (Recivit $囚)$ for treating breakthrough cancer pain. Eur Oncol Haematol 2014;10:12-16.

97 Jandhyala R, Fullarton JR, Bennett MI. Efficacy of rapid-onset oral fentanyl formulations vs. oral morphine for cancer-related breakthrough pain: a meta-analysis of comparative trials. J Pain Symptom Manage 2013;46:573-80. 